\title{
THE INFLUENCE OF TEMPERATURE ON THE DEVELOPMENT OF A MENDELIAN CHARACTER
}

\author{
MILDRED A. HOGE \\ From the Zoölogical Laboratory, Columbia University \\ FORTY-TWO FiguRES (FIVE PLATES)
}

CONTENTS

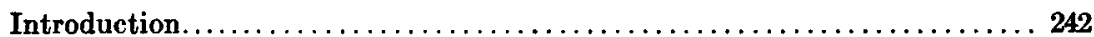

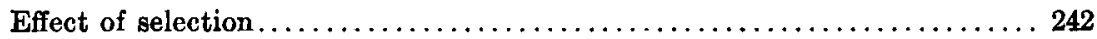

A mutation causing reduplication in the legs $\ldots \ldots \ldots \ldots \ldots \ldots \ldots \ldots \ldots, 245$

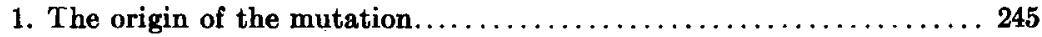

2. Specific types of abnormalities not inherited............... 246

3. The apparently changing dominance of the new character........ 247

4. Sex linkage of the new factor, A, at first obscured by the phenomenon of non-disjunction................................ 250

5. Females, homozygous for abnormal, may be normal ............ 252

Influence of the environment on the dominance of abnormality........ 255

1. The changing dominance at least partially dependent upon the temperature..................................... 255

2. Low temperature more effective if the developing flies are cooled at early stages....................................... 256

3. Low temperature more effective if maintained throughout development............................................ 259

Low temperature without effect on wild stocks...................... 260

Selection and mutation. .................................. 261

1. Repetition of selection of wild stocks not followed by mutation.....261

2. Selection in the reverse direction also not followed by mutation..... 261

The linkage between the factor for reduplication and other sex-linked factors. . 262

The factor for reduplication a semi-lethal . . . . . . . . . . . . . . . . . . . 267

Symmetry of reduplicated parts............................. 270

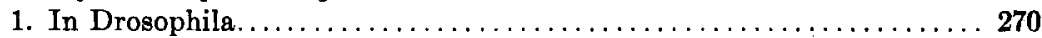

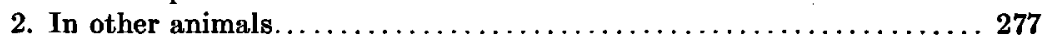

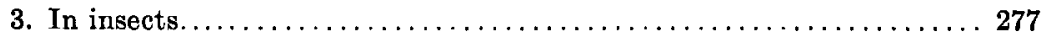

4. Comparison between the extra appendages of Drosophila and other animals..................................... 279

5. Comparison with the regeneration experiments of Tornier......... 279 
Inheritance of reduplications in other animals $\ldots \ldots \ldots \ldots \ldots \ldots \ldots \ldots \ldots 28$

1. Inheritance of extra toe in fowls ........................... 282

2. Inheritance of polydactyly in man......................... 283

3. All reduplications not dominant characters..................... 294

Summary ................................................ 284

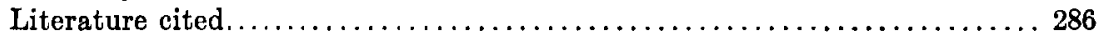

\section{INTRODUCTION}

A new mutation in Drosophila ampelophila, which took the form of reduplication in the legs, appeared in a selection experiment. It was inherited, although at first it did not seem to give the ordinary Mendelian ratios. Many unsuccessful efforts to obtain pure stock were made, and, even after selection for many generations, a single pair of abnormal flies would produce both normal and abnormal offspring. It finally became clear that a low temperature was necessary for the realization of the abnormal type. The stock which had undergone mutation was the only one to develop the reduplications when subjected to a low temperature. A definite sex-linked factor was found to be responsible for the inheritance of this peculiarity.

I wish to thank Dr. T. H. Morgan, under whose direction the work was carried on, for his many helpful suggestions and valuable criticisms.

\section{EFFECT OF SELECTION}

DeVries and Johannsen hold that, in the absence of mutation, selection can do nothing but sort out from a population characteristics already existing. According to this conception, any population may be made up of a series of forms, and this series may be broken up into smaller groups by selection, but the limit of variability can not be transcended. The most extreme individuals in a race produced by such a sorting-out process are no more extreme than the most extreme in the heterogeneous population. Recently Castle and others have endeavored to show that selection may affect the degree of development of the character selected. 
My work began with a study of the effect of selection on the number of 'teeth' in the sex-comb of Drosophila. The sex-comb is confined to the male, and is situated on the first tarsal segment of the first pair of legs. The 'teeth' composing the sex-comb are modified bristles. As the female has no sex-comb, the selection was necessarily confined to the males, and it was further restricted to the comb on the right leg. The legs of fifty wild males were examined, and the teeth in the combs counted. The average number was found to be 10 . At the close of the selection another count of wild flies was made and the number was found to be nearly the same, viz., 9.9 .

TABLE 1

Showing average number of teeth in sex-comb; obtained by selection for high number of teeth for seven generations

\begin{tabular}{ccccc}
$\mathbf{P}$ & $\mathbf{F}_{1}$ & $\mathbf{F _ { 2 }}$ & $\mathbf{F}_{3}$ & $\mathbf{F}_{4}$ \\
11.00 & 10.91 & 11.16 & 11.35 & 11.78 \\
& & & \\
$\mathbf{F}_{5}$ & & $\mathbf{F}_{6}$ & $\mathbf{F}_{7}$ & \\
11.86 & & 11.41 & 11.56 & \\
11.88 & 11.50 & 11.30 & \\
11.67 av. 11.66 & 12.15 av. 11.85 & 11.50 \\
11.58 & 12.70 & 11.42 \\
11.33 & 11.50 & 11.38 av. 11.37 \\
\hline 5 bottles & 5 bottles & 11.42 \\
& & 11.22 \\
& & 11.34 \\
& & 11.18 \\
& & 9 bottles
\end{tabular}

Twenty-four individuals from the wild stock were mated in pairs to wild females. Most of the males selected had eleven teeth. As one of the twenty-four lines yielded better results than any of the others, selection was continued in this line only. The average number of teeth in $F_{1}$ was 10.91. Those with the highest number of teeth in the comb were selected for breedjng. They were mated to sister females. The average number of teeth of their sons was 11.16. Those lines which had failed in $F_{2}$ to be high producers were thrown away. Selection was 
continued for seven generations, sisters of the males being used in each mating. After the $F_{1}$, the average number of teeth showed a steady increase, the highest number-11.85-being reached in the sixth generation. Some bottles in this generation produced an average of over 12 teeth. The mean number in the seventh generation fell somewhat lower-11.37. However, the average number of teeth in this generation, the last one bred,

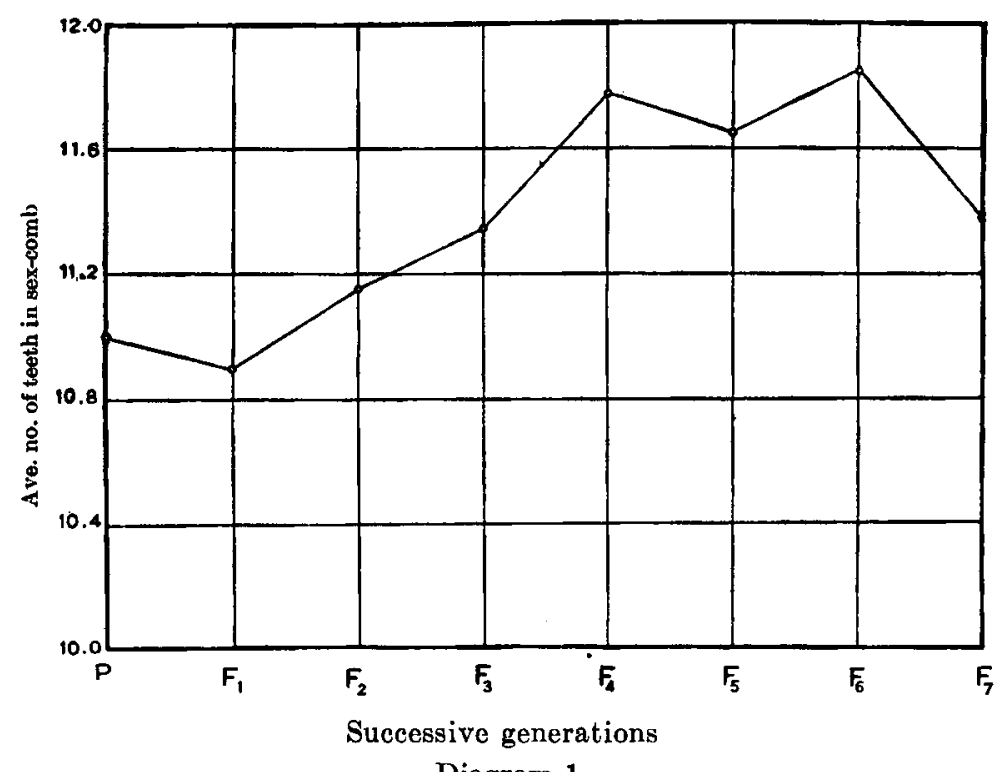

Diagram 1

was nearly 0.4 higher than that of the ancestor (11) and was 1.37 higher than that of the average wild fly. The results of the selection are plotted in diagram 1.

Artificial selection has thus brought about a line of flies having a larger sex-comb than that of the average wild fly. The result is in harmony with the view that selection is only a sorting out process, for although the average had been raised, yet the largest number of teeth in the selected line was no higher than the largest number in the wild stock. 


\section{The origin of the mutation}

When the selection had proceeded to the fifth generation, several abnormal males appeared in the stock. The abnormalities were all connected with reduplication of leg or tarsal segments. In one of the mutants, the left leg was divided, nearly to its base, into two parts, each with a perfect sex-comb. On the right tarsus of the same fly were two combs, one placed above the other. The other mutants showed various kinds of reduplication in the appendages. They were bred to sisters; of the $F_{1}$, 13.9 per cent were abnormal. The $F_{1}$ normals were inbred and abnormalities in the legs appeared again in $F_{2}$. The $F_{2}$ normals were inbred; and later the $F_{3}$ normals and $F_{3}$ abnormals. The result was as follows:

$$
\text { From } \begin{array}{r}
P \ldots \ldots \ldots \ldots 13.9 \text { per cent abnormals in } F_{1} \\
F_{1} \text { normal } \ldots \ldots \ldots .3 \text { per cent abnormals in } F_{2} \\
F_{2} \text { normal } \ldots \ldots 1.7 \text { per cent abnormals in } F_{3} \\
F_{3} \text { normal } \ldots \ldots \ldots 1.7 \text { per cent abnormals in } F_{4} \\
F_{3} \text { abnormal } \ldots \ldots 2.02 \text { per cent abnormals in } F_{4}
\end{array}
$$

The $\mathrm{F}_{3}$ normals produced nearly as many abnormals as did the $\mathrm{F}_{3}$ abnormals. Among the abnormal flies there was a wide range of variation, but usually only one or two extra parts were found in a single fly. The abnormalities occurred most frequently in either the left or the right anterior leg, but the other legs also were sometimes affected. At times the tarsus alone was affected, and at other times the leg as well. Often only one leg was affected but sometimes both anterior legs and sometimes nearly all the legs showed reduplications. The first mutants were males, and only after much inbreeding were abnormal females obtained.

In order to test whether there might be in the cultures some special condition that caused the abnormalities, a stock bottle was allowed to become dry, and wild flies were then transferred to it with fresh food. When their progeny hatched, no abnormal flies were found among them. 


\section{Specific types of abnormalities not inherited}

Since the number of abnormal flies obtained by inbreeding was small, and since there was such a variety in the form assumed, it seemed at first possible that many factors might be involved. Attempts were therefore made to obtain different lines, each with a specific kind of reduplication. Thus, two flies having a bifid first right leg were mated together, or similarly, two flies having a left duplex tarsus. In the following cases of this kind, only the abnormal offspring will be considered:

(1) Two flies, both with right first leg affected, produced among the $F_{1} 4$ abnormals, all with left first leg affected.

(2) Six flies with either right first, left first, or both right first and left first affected were mated. They produced 11 abnormals, as follows:

4 flies with reduplication in right first

4 flies with reduplication in left first

1 fly with reduplication in right and left first

$1 \mathrm{fly}$ with reduplication in left second

$1 \mathrm{fly}$ with reduplication in right first and right second

(3) Three $F_{1}$ flies $\left(2 \%, 1 \sigma^{7}\right)$ all with right first affected produced:

3 flies with reduplication in right first

3 flies with reduplication in left first

1 fly with reduplication in right third

1 fly with reduplication in right second, left first

(4) Parents - males and females with right first or left first, or both, affected produced 7 abnormals as follows:

2 flies with reduplication in left first

2 flies with reduplication in right first

1 fly with reduplication in right second

1 fly with reduplication in right first and right third

$1 \mathrm{fly}$ with reduplication in right first and left first

(5) Parents abnormal-with reduplication in right first or left first produced 42 abnormals as follows: 
5 flies with reduplication in right first

7 flies with reduplication in left first

4 flies with reduplication in left third.

2 flies with reduplication in right third

2 flies with reduplication in left second

1 fly with reduplication in left third, right second

1 fly with reduplication in right first, right third

(6) Parents-males and females with right first affected produced 9 abnormals, viz:

4 flies with reduplication in left first

2 flies with reduplication in left third

$1 \mathrm{fly}$ with reduplication in left first, right first

$1 \mathrm{fly}$ with reduplication in right first

$1 \mathrm{fly}$ with reduplication in left second

The results thus indicate that the particular abnormalities which appear in the offspring of abnormal flies have no relation to the particular abnormalities of the parents.

\section{The apparently changing dominance of the new character}

When bred to wild females, the abnormal males produced all normals in $F_{1}$. In $F_{2}$ there were 1110 normals and 17 abnormals. The abnormality acted apparently as a recessive character. Its appearance in the $F_{1}$ when the original male mutants were bred to sisters was thought to be due to the heterozygous condition of the females.

To obtain pure stock I selected the abnormal flies throughout the summer of 1912. In each generation, the abnormals were separated and mated to other abnormals. The work was done both in pairs and in mass cultures. The per cent of abnormal individuals varied greatly from one generation to another, but never approximated to 100 per cent.

In the fall of 1912, after many apparently unsuccessful attempts to get pure stock, I began experimental work. Crosses with the wild gave the results in table 2. Abnormal males were mated with wild females and abnormal females with wild males. Since a few abnormal males and females appeared in the $F_{1}$ of both 
crosses, it seemed that the factor causing reduplication was not sex-linked, and not always recessive to the wild, but on the other hand, if the character was a non-sex-linked dominant, it was difficult to see why such a small number of abnormals appeared.

Back-crosses were then made by mating the $F_{1}$ flies recorded in table 2 both with abnormal and with wild flies. These crosses

TABLE 2

Cross I

$P$ Abnormal $\sigma^{\nearrow}$ by normal (wild) 우

\begin{tabular}{|c|c|c|c|c|c|c|c|}
\hline & & & & & & & Total \\
\hline & Normal $\sigma^{7}$. & 27 & 85 & 84 & 122 & 114 & 432 \\
\hline & Normal $q, \ldots \ldots \ldots \ldots \ldots \ldots$ & 15 & 99 & 100 & 151 & 140 & 505 \\
\hline & Abnormal o $\sigma^{7} . . . \ldots \ldots \ldots$. & & & 3 & & 6 & 9 \\
\hline & Abnormal $q \ldots \ldots \ldots \ldots \ldots$ & & 1 & & & & 1 \\
\hline & Normal $\sigma^{7} \ldots \ldots \ldots \ldots \ldots \ldots$ & 229 & 126 & & 16 & 101 & 472 \\
\hline $\mathbf{F}_{2}$ & Normal $q \ldots \ldots \ldots \ldots \ldots \ldots$ & 265 & 136 & & 38 & 173 & 612 \\
\hline & Abnormal o $\sigma^{x}$. & 13 & 7 & & 3 & 18 & 41 \\
\hline
\end{tabular}

Cross II

$P$ Abnormal o by normal (wild) $\sigma^{7}$

\begin{tabular}{|c|c|c|c|c|c|}
\hline \multirow{4}{*}{$\mathbf{F}_{1}$} & & & & & Total \\
\hline & Normal ó... & 33 & 34 & 93 & 160 \\
\hline & 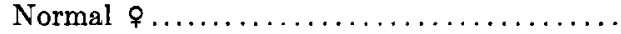 & 45 & 84 & 151 & 280 \\
\hline & Abnormal $\sigma^{\top} \ldots \ldots \ldots \ldots \ldots \ldots \ldots \ldots \ldots$ & & 19 & 33 & 52 \\
\hline & Abnormal \&............ & & 1 & 12 & 13 \\
\hline & 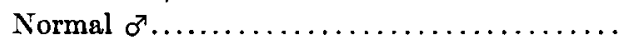 & & 72 & & \\
\hline & Normal $q \ldots \ldots \ldots \ldots \ldots \ldots \ldots \ldots \ldots \ldots \ldots$ & & 114 & & \\
\hline & Abnormal $\sigma^{7} \ldots \ldots \ldots \ldots \ldots \ldots \ldots \ldots \ldots \ldots$ & & 26 & & \\
\hline & Abnormal $\&$.. & & 2 & & \\
\hline
\end{tabular}

Cross III

$P$ Abnormal red ${ }^{\nearrow}$ by normal white \%

\begin{tabular}{|c|c|c|c|c|c|}
\hline & & & & & Total \\
\hline & Normal white $\sigma^{a}$ & 10 & 96 & 89 & 195 \\
\hline F & Normal red $\%$. & 15 & 107 & 73 & 195 \\
\hline & Normal red $\sigma^{\top}$. & 27 & $\mathbf{5 7}$ & 40 & 124 \\
\hline & Normal white $\sigma^{x}$. & 23 & 69 & 46 & 138 \\
\hline & Normal red $\$$... & 35 & 95 & 80 & 210 \\
\hline & Normal white $\%$. & 35 & 85 & 78 & 198 \\
\hline & Abnormal red $\sigma^{\pi}$. & 1 & 17 & 3 & 21 \\
\hline & Abnormal & 1 & 15 & 4 & 10 \\
\hline
\end{tabular}


again made it clear that abnormality behaves differently at different times. The following cases illustrate this. From two of the back-crosses (table 3 , Series $b$ ) in which normal $F_{1}$ flies were mated to wild flies, $F_{2}$ abnormals resulted. The $F_{1}$ flies had only one dose of the factor and were normal, yet some of their offspring had one dose and were abnormal. A normal

TABLE 3

Series a P Abnormal ơ by wild $\$$ (Crosses I and III of table 2 )

$F_{1}$ Normal o by $F_{1}$ Normal or $F_{1}$ Normal $\&$

wild $\$$ ( 5 bot- by abnormal by abnormal tles) \% (5 bottles) ơ ( 3 bottles)

$F_{2} \begin{cases}\text { Normal } & \sigma^{\top} \ldots \ldots \ldots \ldots \ldots \ldots \\ \text { Normal } q \ldots \ldots \ldots \ldots \ldots & 222\end{cases}$ $49^{*} \quad 157$ $228 \quad 171$ Abnormal $\sigma^{7} \ldots \ldots \ldots \ldots \ldots \ldots$

Abnormal $9 . . . \ldots \ldots \ldots$.

$\mathbf{3 0}$

Series b $P$ Abnormal o by wild ơ (Cross II of table 2$)$

$F_{1}$ Normal or $F_{1}$ Normal $q$ F $F_{1}$ Normal $q$ by wild $\&$ ( 3 by wild ơ ( 2 by abnormal bottles)

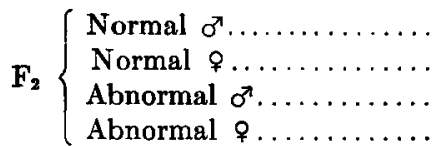

229

230 bottles)

22 o (1 bottle) $18 \dagger$

121 21 34 29 53

* One of these 49 normal males was bred to a wild female and produced abnormal flies in the next generation. This normal male was thus potentially abnormal.

$\dagger$ These 18 males were all from one of the three bottles.

$\mathrm{F}_{2}$ male from Series a was tested for abnormality by breeding to a wild female, and abnormal flies were produced in the next generation. The $F_{2}$ male though normal, must have carried the factor for abnormality. An $F_{1}$ normal female (Series $b$ ) was back-crossed to an abnormal male. Over half the flies of $F_{2}$ were abnormal, though only half could have been homozygous. The $F_{1}$ female must have been heterozygous and yet she was normal. It is evident, then, that a fly may be heterozygous and either normal or abnormal, and in other words, the character may sometimes act as a dominant and sometimes as a recessive. 
4. Sex-linkage of the new factor, $A$, at first obscured by the phenomenon of non-disjunction

Though the first work seemed to indicate that the factor for abnormality, which we will call $A$, was not sex-linked, the backcrosses threw doubt on this conclusion. For example, $F_{1}$ normal males, from cross abnormal male by wild female, were mated to wild females (table 3, Series a). From this cross were hatched 491 flies, and these were all normal. If the A factor is not sexlinked, why did the $F_{1}$ males not transmit it to any of their offspring? If it is sex-linked, then none of the $F_{1}$ males used in this cross carried the factor, since the one sex-chromosome carried by each male came from his mother, who was wild. On this hypothesis, we should expect no abnormal males from the cross $F_{1}$ normal male by wild female (table 3 , Series $b$ ). From two of the three bottles of this cross, no abnormal males hatched. However, 18 abnormals, out of a total of 224 flies, hatched from the third bottle. It will be noticed, also, that abnormal males appeared in two of the eight bottles (table 2, Crosses $I$ and III) among the $F_{1}$ of the cross abnormal male by wild female (red or white). These cases were difficult to explain on the theory that the factor is sex-linked, and yet the other cases, where no abnormal males appeared, were difficult to explain on any other theory. The results thus far were perplexing.

The appearance of the small number of abnormal males in the above experiment, where no abnormal males are expected, may be explained on Bridges' hypothesis of non-disjunction of the sex chromosomes (Jour. Exp. Zoöl., vol. 15, no. 4). On this view, the two sex-chromosomes sometimes stick together and either remain in the egg when the polar bodies are formed, or else both are eliminated. Should an egg from which both of the sexchromosomes have been removed be fertilized by a femaleproducing spermatozoan from the abnormal male-a spermatozoan that carries the sex-chromosome-an abnormal male would be produced. If abnormal males should appear frequently in the $F_{1}$ when the father only is abnormal, one would not be justified in applying this hypothesis, for non-disjunction is a 
rather rare occurrence. I therefore repeated the preceding cross (abnormal male by wild female) using both normal (wild) and normal white eyed females. No abnormals appeared among the 539 males in the $F_{1}$ (see table 4, Cross I). Each fly was carefully examined twice to eliminate possible error. To leave no doubt whatever, the $F_{1}$ normal males were bred in pairs to wild females (table 4, Cross II). No abnormal flies, male or

\section{TABLE 4}

Cross I
$P$ Abnormal ơ by wild red 9
$P$ Abnormal or by normal white ?
F1 $\left\{\begin{array}{llrrrr}\text { Normal } & \text { or..... } & 91 & 144 & 158 & 393 \\ \text { Normal } & \text { \&..... } & 104 & 173 & 154 & 431\end{array}\right.$

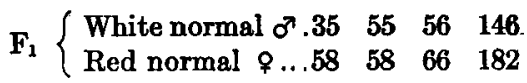
Cross II

$F_{1}$ Normal $\sigma^{7}$ (from Cross I) by wild \&

$\begin{array}{llllrr}F_{2} \text { Normal (or and \&) . ....1474 } & 751 \quad 635 & 355 & 3215\end{array}$

Cross III

$F_{2}$ Normal ơ (from Cross II) by $F_{2}$ normal $q$

\begin{tabular}{cccccc}
$F_{3}$ Normal (o and $\left.\uparrow\right) \ldots \ldots . \ldots 375$ & 332 & 942 & 254 & 1903 \\
\multicolumn{4}{c}{ CRoss IV }
\end{tabular}

$F_{1}$ Normal $\&$ (from Cross I) by wild $\sigma^{\pi}$

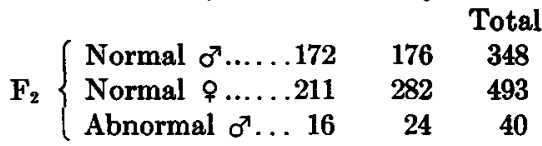

female, appeared in the $F_{2}$, and, when these were inbred, no abnormals were found in the $\mathrm{F}_{3}$ (table 4 , Cross III). In this experiment non-disjunction males did not appear, for none of the $F_{1}$ males had received a chromosome containing the factor for abnormality. The $F_{1}$ females, on the other hand, when bred to wild males, produced some abnormal $\mathrm{F}_{2}$ males (table 4, Cross IV), thus revealing clearly the essential difference between the inheritance of sons and daughters. Since an abnormal male can 
transmit the factor for abnormality to his daughters only (except in rare cases, which may be explained by non-disjunction) the factor must be sex-linked. This conclusion was justified by subsequent work.

\section{Females, homozygous for abnormal, may be normal}

It has been shown that one dose of the factor A does not always produced abnormality. Even a double dose may not cause any abnormality, as is shown in the following experiment. Two abnormal males were bred separately to two wild females. The $F_{1}$ females, which were heterozygous, were then crossed to abnormal males. Half of the $\mathrm{F}_{2}$ females were therefore homozygous, and half heterozygous for abnormality. The results are given in table 5 .

TABLE 5

$P$ Abnormal or by wild $\%$

$F_{1} \odot$ (from above cross) by abnormal male

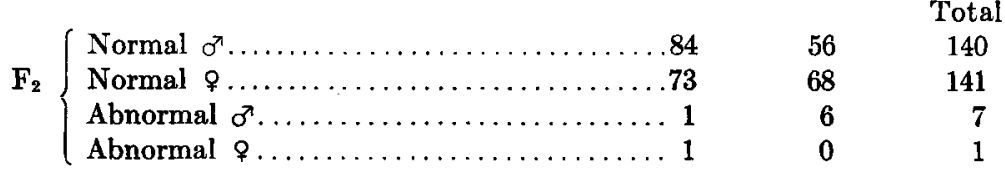

Thus only one of the females showed any abnormality, though every one carried at least one dose of the factor. Eighteen of the normal $\mathrm{F}_{2}$ females were bred in pairs to wild males, with the following result:

$F_{2}$ Normal $\&$ (from above) by wild $\sigma^{x}$

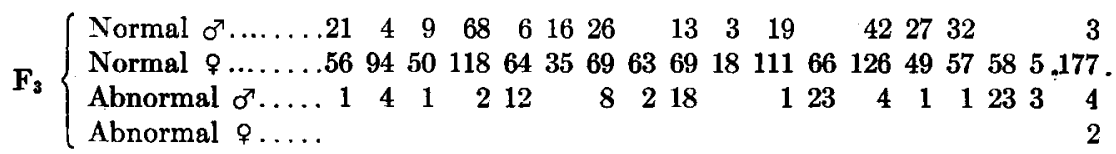

Sixteen of the normal $F_{2}$ females thus produced abnormal males. Only a small number of males hatched, indicating that the factor for abnormality may act as a semi-lethal factor. In four of the eighteen bottles, all the males which hatched were 
abnormal. In these four cases, at least, the $F_{2}$ female must have been homozygous, as otherwise some of her sons would have been normal. It is thus evident that a female homozygous for abnormal may be normal.

These results throw light on the following tests of the normal and abnormal progeny of abnormal parents (table 6). Abnormal males and females were bred in.pairs. $F_{1}$ normal males from this cross were bred to $F_{1}$ normal females, and $F_{1}$ abnormal males to $F_{1}$ abnormal females. Many of the $F_{1}$ abnormals either died

TABLE 6

P Abnormal ơ by abnormal 우

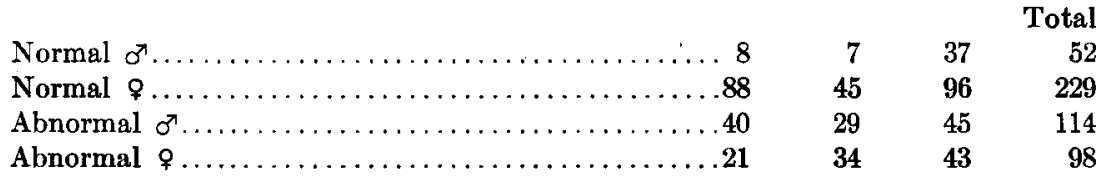

$F_{1}$ Abnormal or by $F_{1}$ abnormal q

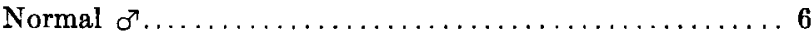

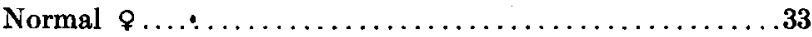

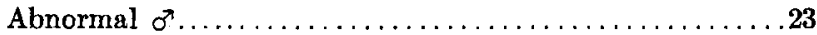

Abnormal $\$ \ldots \ldots \ldots \ldots \ldots \ldots \ldots \ldots \ldots \ldots \ldots \ldots$

$\begin{array}{rr}1 & 7 \\ 35 & 68 \\ 3 & 26 \\ 18 & 22\end{array}$

$F_{1}$ Normal $\sigma$ by $F_{1}$ normal $q$

\begin{tabular}{|c|c|c|c|c|c|c|c|c|c|}
\hline Normal $\sigma^{\top}$. & .20 & 17 & 15 & 49 & 53 & 84 & 54 & 62 & 354 \\
\hline Normal $\&$. & .52 & 74 & 38 & 80 & 96 & 130 & 103 & 99 & 672 \\
\hline Abnormal $\sigma$ & .21 & 12 & 25 & 38 & 24 & 19 & 28 & 32 & 199 \\
\hline Abnormal & 3 & 3 & 28 & 8 & 8 & 8 & 17 & 18 & \\
\hline
\end{tabular}

or were infertile, but those that were fertile produced in $\mathrm{F}_{2} 39$ per cent of abnormal individuals. The $F_{1}$ normals of the same parentage produced, when inbred, only 22.1 per cent of abnormal individuals. Abnormal offspring of abnormal stock thus yield more abnormals than do normal offspring. The reason for this becomes apparent when we consider that the stock had not then been proven to be pure. Among the parent abnormals were therefore probably both homozygous and heterozygous individuals, and when the $F_{1}$ were chosen, some of the normals among them may have been true normals, whereas the $F_{1}$ abnormals chosen were at least heterozygous for $\mathrm{A}$. 
The proportion of abnormal flies in the stock bottles varied from time to time. Records of the stock showed that it might yield a high per cent one month and a low per cent the following month. Also, the flies in any one stock were of varied types. Some were only slightly abnormal, and some were so abnormal that they could scarcely walk. The slightly abnormal produced progeny as abnormal as that of the very abnormal. This was shown by the following tests, $a$ and $b$.

Test a. A slightly abnormal male was mated to a slightly abnormal female, and a very abnormal male to a very abnormal female:

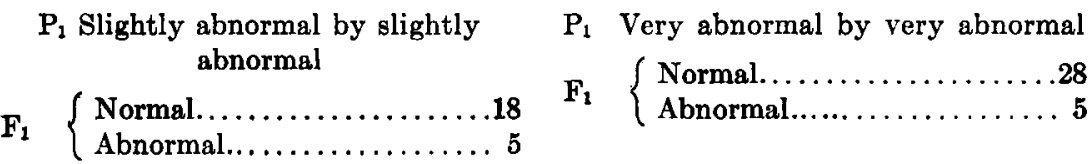

The abnormalities in the two cases were similar;

From slightly abnormal parents

4 flies showing reduplication in 1st left leg

1 fly showing reduplication in $3 \mathrm{~d}$ right leg
From very abnormal parents

3 flies showing reduplication in 1st left leg

2 flies showing reduplication in 1st right leg

Test $b$. A stock which was yielding only a small percentage of abnormals was divided into two parts. The least abnormals were inbred and the most abnormals were inbred:

$\begin{array}{lccc} & \text { Normal } & \text { Abnormal } & \begin{array}{c}\text { Per cent of } \\ \text { abnormal }\end{array} \\ \text { From the most abnormal } F_{1} \ldots \ldots \ldots \ldots \ldots & 386 & 110 & 22.2 \\ \text { From the least abnormal } F_{1} \ldots \ldots \ldots \ldots \ldots \ldots & 400 & 119 & 22.9\end{array}$

The degree of abnormality and the per cent of abnormal offspring were thus approximately the same, whether the parents were very abnormal or only slightly so. 
INFLUENCE OF THE ENVIRONMENT ON THE DOMINANCE OF ABNORMALITY

1. The changing dominance at least partly dependent upon the temperature

As has been said, the proportion of abnormal flies in the stock showed considerable variation, and on two occasions the abnormalities almost disappeared. In the summer of 1912, shortly after the appearance of the mutation, an apparent 'reversion' to the normal type took place, and only a few abnormals hatched. After careful selection and inbreeding of these, the abnormalities in the stock returned. Again, in the spring of 1913, as the warm weather came on, a similar 'reversion' took place, though some

TABLE 7

\begin{tabular}{|c|c|c|c|c|c|c|c|}
\hline \multicolumn{4}{|c|}{ DEVELOPED AT REDUCED TEMPERATURE } & \multicolumn{4}{|c|}{ DEVBLOPED AT ROOM TFMPERATURE } \\
\hline & Normal & Abnormal & $\begin{array}{c}\text { Percentage } \\
\text { of } \\
\text { abnormal }\end{array}$ & & Normal & Abnormal & $\begin{array}{l}\text { Percentage } \\
\text { of } \\
\text { abnormal }\end{array}$ \\
\hline Stock a... & 46 & 44 & 48.8 & Stock a.... & 235 & 43 & L5.4 \\
\hline Stock b... & 33 & 71 & 68.2 & Stock b. . . & 90 & 11 & 10.8 \\
\hline Stock c... & 198 & 87 & 30.5 & & & & \\
\hline
\end{tabular}

abnormal flies were found in all the bottles. Stocks which had been yielding a fairly large per cent of abnormal flies now yielded only a few. Since in both cases the 'reversion' took place at the approach of warm weather, it seemed possible that temperature affected the production of the abnormal flies. To test this assumption, mass cultures from several stocks were placed in an ice chest and kept there until the pupae had developed, when they were removed to room temperature. The result was decisive. The per cent of abnormal flies was from three to six times that of the controls which were taken from the same stocks and kept at room temperature (table 7).

Many things obscure up to this time became clear. For example, the fact that a male carrying the factor for abnormality or a female carrying one or two doses of this factor might be either 
abnormal or normal, became obvious when the effect of the environment was taken into consideration. The unsuccessful attempts to obtain pure stock were evidently due to unfavorable environmental conditions. If this were the case, the stock, which had been selected for many generations, was most probably pure.

Pure stock was readily obtained by inbreeding pairs of the $F_{1}$ abnormals of abnormal parents and allowing the $F_{2}$ to develop in the ice box. The best record so obtained was as follows:

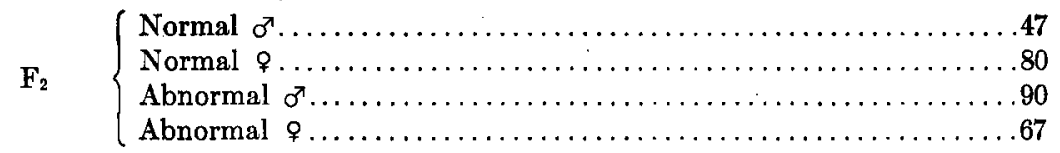

The $F_{1}$ female used must have been homoyzgous, for otherwise the per cent of abnormal males would not have been over $\mathbf{5 0}$ per cent. The pure stock thus obtained was used as a basis for all the remainder of the experimental work.

Many of the iced flies showed a greater degree of abnormality than any of those which had been previously studied. In many cases the legs were mere stumps and the flies could not hatch normally. When the pupa cases opened, the flies were drawn out of them with needles and these flies, almost without exception, proved to be very abnormal and incapable of locomotion.

Up to this point only the general influence of the cold was understood. The bottles put on ice had been kept there until the pupae were well formed. The following questions arose: (1) At what stage in the development must the cold be applied?

(2) How long must the developing flies be left in the jce box in order to become abnormal?

\section{Low temperature more effective if the developing fies are cooled at early stages}

To answer these two questions, two series of experiments were undertaken. For both of these pure stock only was used. In the first experiment, pairs of the pure stock were mated, and in most cases, allowed to remain in the bottles for only one day. 
This was done so that the eggs in one bottle would be approximately the same age. In some cases, the parents remained in the bottles two, three and four days. In all cases the average time of the egg-laying was considered as midway between the time when the parents were placed in the bottle and the time when they were taken from the bottle. The number of eggs was not counted. After the parents had been removed, the bottles were kept at room temperature and then put on ice at stated periods. Some were put in the cold immediately, and others were kept at room temperature from one to nine days before they were placed in the cold. After the eggs or larvae had been put into the ice chest, they were not removed, except to add food, until

TABLE 8

\begin{tabular}{|c|c|c|c|}
\hline \multirow{2}{*}{ Age of eggs or larvae when cooled } & \multirow{3}{*}{$\begin{array}{c}\text { Total } \\
12\end{array}$} & \multirow{2}{*}{\multicolumn{2}{|c|}{$\begin{array}{c}\text { Per eent o } \\
\text { abnormal abnol }\end{array}$}} \\
\hline & & & \\
\hline$\frac{3}{2}$ day. & & 12 & 100.0 \\
\hline $1 \frac{1}{2}$ to 2. . & 506 & 341 & 67.4 \\
\hline $2 \frac{1}{2}$ to 3. & 290 & 148 & 51.0 \\
\hline $3 \frac{1}{2}$ to $4 \ldots$ & 417 & 98 & 23.5 \\
\hline $4 \frac{1}{2}$ to $5 \ldots$ & 699 & 80 & 11.4 \\
\hline$\ldots \ldots \ldots \ldots \ldots$ & 752 & 79 & 10.5 \\
\hline $6 \frac{1}{2}$ to $7 \ldots$ & 510 & 43 & 8.4 \\
\hline$\ldots \ldots \ldots \ldots \ldots \ldots \ldots \ldots$ & 960 & 116 & 12.1 \\
\hline$\ldots \ldots \ldots \ldots \ldots \ldots \ldots \ldots \ldots$ & 306 & 33 & 10.8 \\
\hline$\ldots \ldots \ldots \ldots \ldots \ldots \ldots \ldots \ldots$ & 393 & 15 & 3.8 \\
\hline Control, not cooled... & 1711 & 174 & 10.1 \\
\hline
\end{tabular}

they had hatched. The temperature of the ice chest was not kept constant, but varied slightly about $10^{\circ} \mathrm{C}$. Controls of the same pure stock were kept at room temperature. In these bottles, the flies emerged in about twelve days. The percentage of abnormal fies which hatched from the iced bottles was found to depend upon the stage at which the cold was first applied. The results are given in table 8 . In those bottles which were put on ice immediately after the mating, many of the flies were infertile, so that the number of $F_{1}$ flies which hatched was very small. However, these were all abnormal. The longer the flies developed at room temperature, or, in other words, the longer the time before they were piaced on ice, the smaller was the nurnber of abnormal flies. The bottles kept in the room six 
days or more than six days developed no more abnormal flies than those kept for the entire time at room temperature. When the larvae were left in the room nine to nine and one-half days, the percentage of abnormal flies fell to 3.8 per cent, but this evidently is not significant, as the total number of flies was small. The small number of abnormals in this case may have been due to an increased room temperature at the time these flies were developing. The results are plotted in diagram 2. The curve

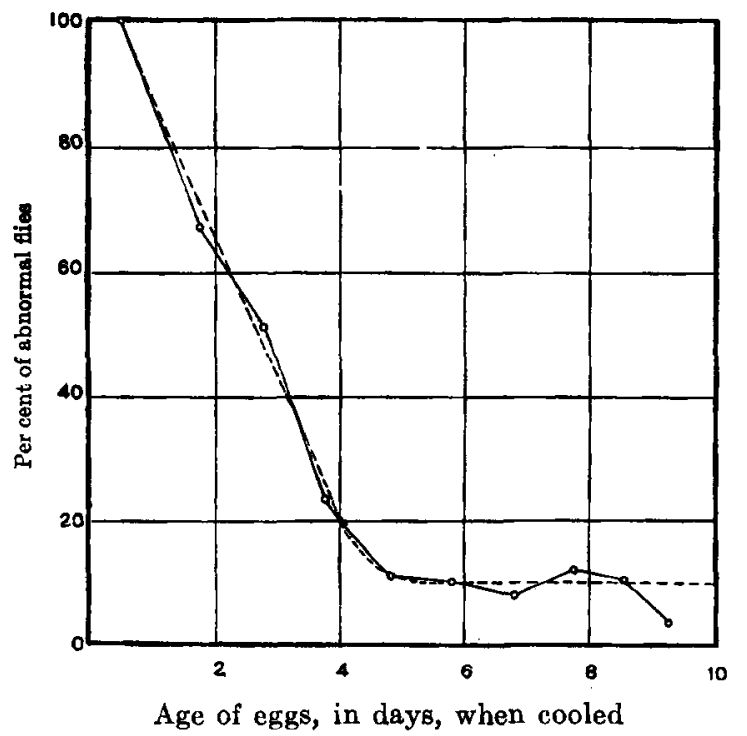

Diagram $2^{1}$

of abnormality shows a rapid fall from its highest point, which represents the number of abnormals when the entire development took place at the low temperature, to a point corresponding to the number of abnormals when the first six days of development took place at room temperature. From this point the curve is nearly parallel to the abscissa. This indicates that low temperature is effective only if first applied at early stages, and that, after the larvae have developed a few days at room temperature, a decrease in temperature is ineffectual in causing abnormalities.

1 Dotted line is theoretical curve. 
3. Low temperature more effective if maintained throughout development

In the second experiment, eggs were put on ice immediately and kept there for different lengths of time, after which they were removed to room temperature for the remainder of their development. Flies of pure stock were placed in bottles containing banana spread out on narrow strips of paper. The food was removed at short intervals, one hour, two hours, etc., though in some cases it remained in the bottles over night. As soon as removed, the food was carefully examined and the eggs were picked from it, one by one, by the aid of a flattened needle, and placed on fresh banana in a clean bottle. Their number was

TABLE 9

\begin{tabular}{|r|r|r|r|r|r|r|r}
\hline DAYB ON ICE & $\begin{array}{c}\text { No. OF } \\
\text { EGGB }\end{array}$ & $\begin{array}{c}\text { NO. EGGS } \\
\text { HATCHED }\end{array}$ & $\begin{array}{c}\text { PFR CENT } \\
\text { HATCHED }\end{array}$ & NORMAZ & ABNORMAL & GUM & $\begin{array}{c}\text { PER CENT } \\
\text { OF } \\
\text { ABNORMAL }\end{array}$ \\
\hline 1 to $5 \ldots .$. & 1370 & 644 & 47.0 & 589 & 44 & 633 & 7.0 \\
6 to $10 \ldots \ldots$ & 608 & 290 & 47.7 & 209 & 77 & 286 & 26.9 \\
11 to $16 \ldots \ldots$ & 260 & 99 & 38.1 & 40 & 50 & 90 & 55.6 \\
22 to $24 \ldots \ldots$ & 46 & 17 & 37.0 & 4 & 8 & 12 & 66.6 \\
32 to $35 \ldots .$. & 44 & 13 & 29.6 & 2 & 9 & 11 & 81.8 \\
\hline
\end{tabular}

recorded. When the eggs were transferred, they were not placed directly on the banana but upon a piece of filter paper placed over the food. This was done to avoid covering the eggs with the food, which may prevent them from hatching. The bottles were then placed on ice. Some were kept there one to five days, others six to ten days, etc. The bottles were then removed to room temperature. Table 9 and diagram 3 give the results. Some of the flies which hatched had lost one or more legs and therefore could not be classed as abnormal or normal. For this reason the 'number hatched' is larger than the sum of abnormal and normal.

The per cent of abnormal flies varied directly with the length of exposure to cold, but the number hatched varied inversely with the length of exposure to cold. As many of those which did 


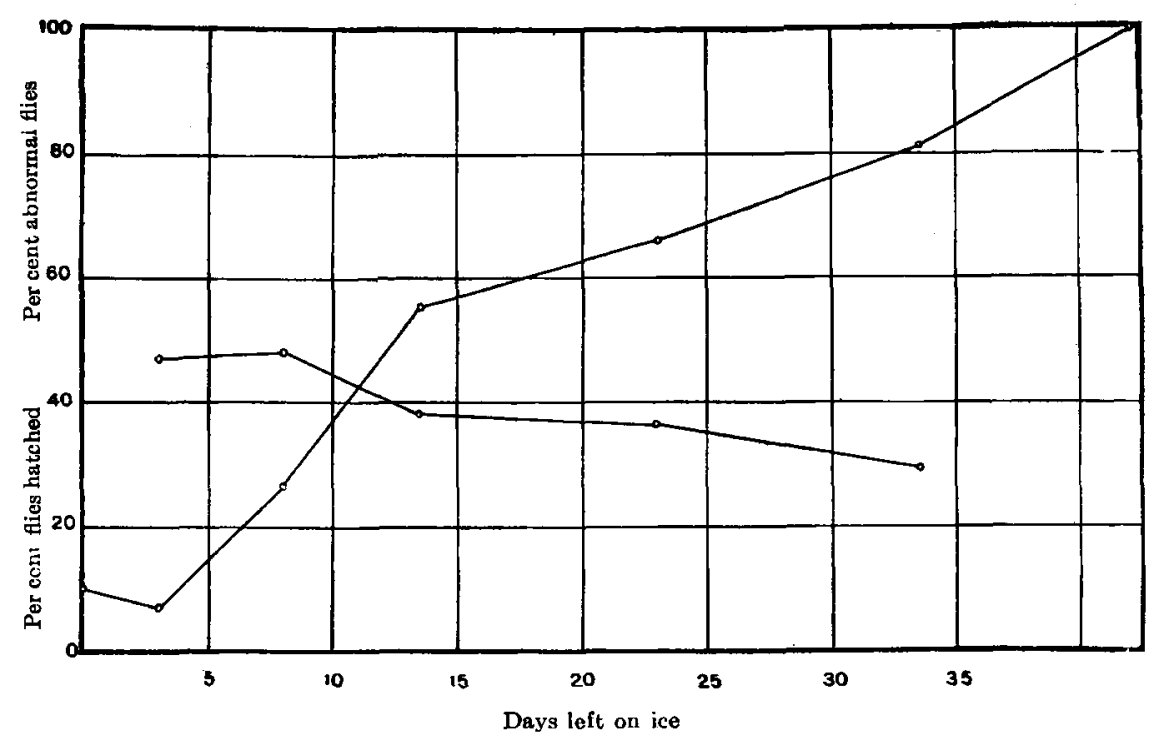

Diagram 3

not hatch would have been abnormal, the percentage of abnormal flies would probably have been larger, had the full number hatched.

These two experiments show conclusively that a temperature of $10^{\circ} \mathrm{C} . \pm$, maintained throughout development, produces a large percentage of abnormal flies.

\section{LOW TEMPERATURE WITHOUT EFFECT ON WILD STOCKS}

Flies from a wild stock were mated, both in pairs and in mass culture and placed in the ice box immediately or several days after mating. The larvae were removed before they hatched. Of the 1352 flies which hatched, only one showed any abnormality. The test was repeated, and this time the eggs were cooled shortly after they were laid, and the pupae were allowed to hatch in the ice box. The 214 flies which hatched were all normal. Low temperature, therefore, does not cause reduplication in normal stock. The one abnormal fly that appeared in the first case was probably due to infection. Possibly it may have been a mutant. On the other hand, the abnormality may 
have been simply a somatic variation, for a few abnormal flies, similar to those of my stock, have been found from time to time in other cultures, but when bred, they have never transmitted the variation.

\section{SELECTION AND MUTATION}

1. Repetition of selection of wild stocks not followed by mutation

As the abnormal flies originally appeared in a selection experiment, it might seem probable that selection had some influence on the appearance of the mutation. Were such the case, the mutation should appear again if the original selection should be repeated. Wild stock was therefore selected, as before, for a high number of teeth in the sex-comb. The selection was carried on even longer than in the first case, but no abnormal flies were discovered.

2. Selection in the reverse direction also not followed by mutation

Selection for the smallest number of teeth in the sex-comb was carried out. From wild stock a number of flies having eight or nine teeth were mated in pairs to wild females. From the $F_{1}$ and succeeding generations the males that had the smallest number of teeth were selected for further mating. Not all the males were examined in each generation, but in the sixth and tenth generations careful counts were made.
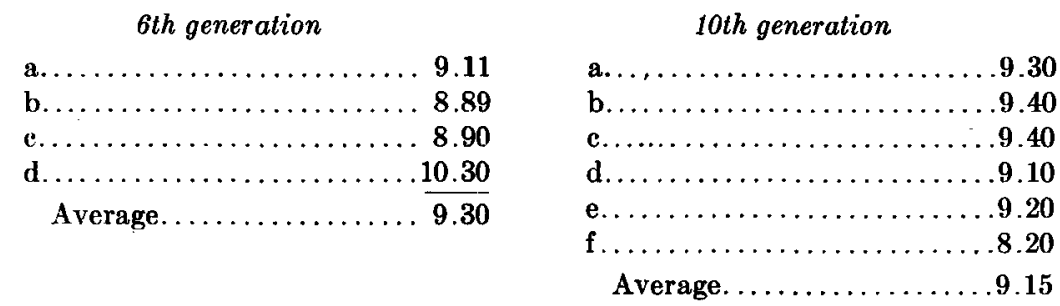

The average number of teeth in the wild stock is ten. Selection downward has brought about a decrease in this number. The flies which hatched in each generation of both this and the previous selections were carefully examined for leg abnormalities, but no mutations in the legs were found. 
As a check on the selection experiments, wild stocks from various localities were examined, and the average number of teeth of 30 to $\mathbf{4 0}$ individuals in each stock thus obtained:

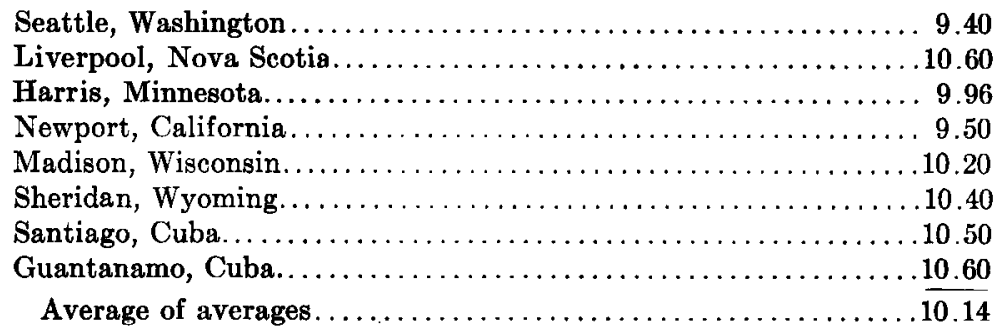

A slight variation thus appears in different stocks, but this may be due to the small number counted.

THE LINKAGE BETWEEN THE FACTOR FOR REDUPLICATION AND OTHER SEX-LINKED FACTORS

Red-eyed abnormal males were crossed to normal females with white eyes or barred eyes or vermilion eyes. These three characters are sex-linked. The first generation was allowed to develop at room temperature. The flies were then mated at room temperature, and later transferred to new bottles and placed in the ice chest, where the eggs were laid. Mating at room temperature was found to be necessary, as it evidently does not take place at the low temperature. The eggs developed very slowly, and, although many reached the late larval, or early pupal stage, development did not proceed farther in most cases. A few flies emerged at the low temperature, but the numbers were too small to be significant. The same matings were then repeated, but with some changes in method. When the $F_{1}$ hatched, they were mated both in pairs and in mass cultures, and then removed not to an ice box, but to a cold room, the temperature of which varied approximately from 10 to $15^{\circ} \mathrm{C}$. After the $\mathrm{F}_{2}$ larvae had pupated (about 20-28 days after mating of $F_{1}$ ) they were removed to the normal room temperature, at which the flies hatched. No attempt was made, as in some of the previous experiments (tables 8 and 9), to have the conditions nearly identical for all the developing flies, as the experiment was planned to obtain 
as many abnormals in $F_{2}$ as possible. Thus, when the bottles were removed to room temperature, although some of the larvae had pupated, others were still in the larval stage. By this method a much larger yield was obtained, and a fair percentage of those which hatched were abnormal.

Two kinds of controls were used. In the first, the $F_{1}$ flies which had laid in the cold room were transferred to new bottles, and a second batch of eggs was laid at normal room temperature, where the entire development took place. For the second control, abnormal flies from pure stock were mated, and kept in the cold room, as in the case of the $F_{1}$ described above. The expectation and the count are as follows:

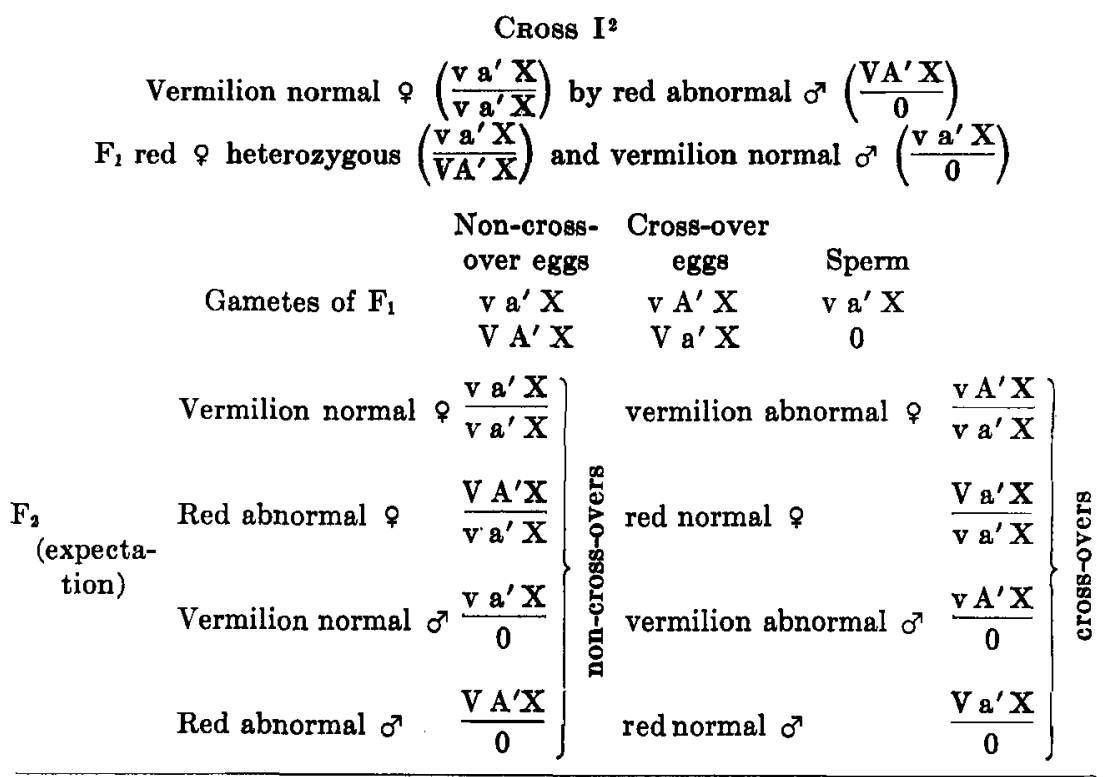

2 The symbols used in the text are as follows: $B r^{\prime}$, dominant factor causing barred eyes; $b r^{\prime}$, its allelomorph in the wild red fly; $w$, recessive factor causing white eyes; $W$, its allelomorph in the wild red fly; $v$, recessive factor causing vermilion eyes; $V$, its allelomorph in the wild red fly; $A^{\prime}$, domtnant factor causing abnormal legs; $a^{\prime}$, its allelomorph in the wild fly. In Crosses I and II, the $F_{1}$ should show complete criss-cross inheritance, the females being like their father and the males like their mother, since the female parent carrried only recessive sex-linked characters. Practically all the $F_{1}$ in all three crosses were normal; since they had developed at room temperature. 
Developed at low temperature

(22 bottles)

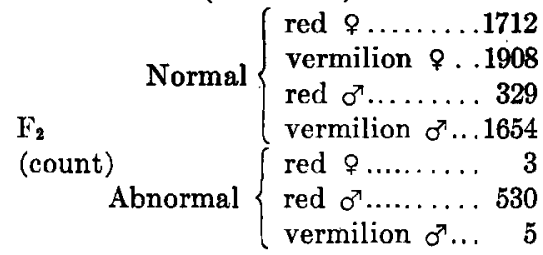

(Control 1)

Developed at room temperature

(18 bottles)

980

1016

611

878

126

6

Total number of non-cross-over abnormal males ${ }^{3} \ldots \ldots \ldots \ldots \ldots \ldots .656$

Total number of cross-over abnormal males. . . . . . . . . . . . . 11

Total number of $F_{2}$ abnormal males....................6. 667

Ratio of cross-overs to total number................. 1.6 per cent

\section{Cross II}

White normal $\&\left(\frac{w a^{\prime} X}{w a^{\prime} X}\right)$ by red abnormal $\sigma^{7}\left(\frac{W A^{\prime} X}{0}\right)$

$F_{1}$ red $\%$ heterozygous $\left(\frac{w a^{\prime} X}{W A^{\prime} X}\right)$ and white normal $\sigma^{\prime}\left(\frac{w a^{\prime} X}{0}\right)$

\section{Non-cross-over Cross-over}

\begin{tabular}{|c|c|c|}
\hline Gametes of $F_{1}$ & $\begin{array}{c}\text { eggs } \\
\mathbf{w} \mathbf{a}^{\prime} \mathbf{X} \\
\mathrm{W}^{\prime} \mathrm{A}^{\prime} \mathrm{X}\end{array}$ & $\begin{array}{c}\text { eggs } \\
\mathbf{w} A^{\prime} X \\
W a^{\prime} X\end{array}$ \\
\hline
\end{tabular}

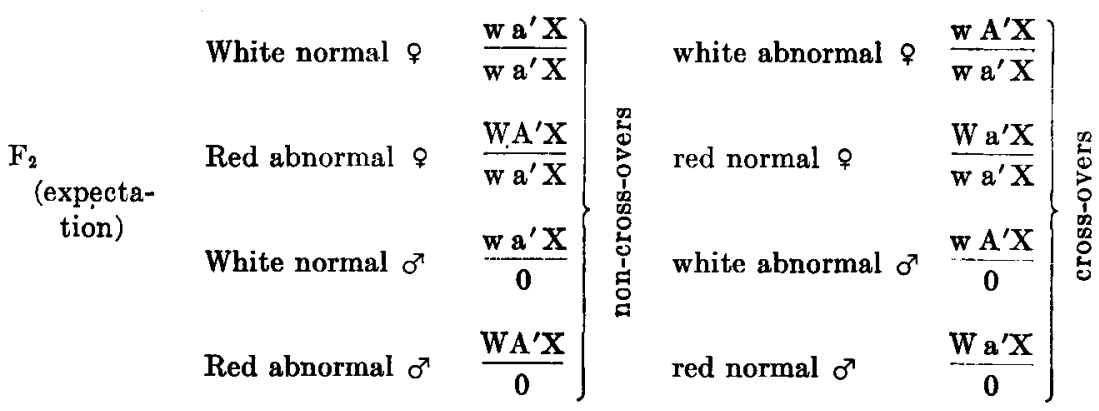

(Control 1)

Developed at low temperature

(18 bottles)

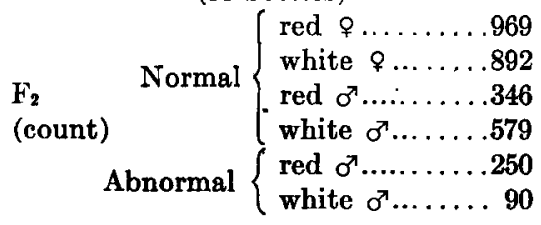

Developed at room temperature

(5 bottles)

352

304

298

298

47

31

3 In calculating the linkage, only the $\mathrm{F}_{2}$ abnormal males are considered. All the $\mathrm{F}_{2}$ abnormal males, whether developed in the cold room or at normal room 
Total number of non-cross-over abnormal males... . . . . . . . . . 297

Total number of cross-over abnormal males. . . . . . . . . . . . . 121

Total number of $F_{2}$ abnormal males $\ldots \ldots \ldots \ldots \ldots \ldots \ldots \ldots \ldots \ldots \ldots 18$

Ratio of cross-overs to total number...........28.9 per cent

Cross III*

Barred normal 우 $\left(\frac{\mathrm{Br}^{\prime} \mathrm{a}^{\prime} \mathrm{X}}{\mathrm{Br}^{\prime} \mathrm{a} \mathbf{a}^{\prime} \mathrm{X}}\right)$ by not-barred abnormal $\sigma^{\prime}\left(\frac{\mathrm{br}^{\prime} \mathrm{A}{ }^{\prime} \mathrm{X}}{0}\right)$

$F_{1}$ barred $q$ heterozygous $\left(\frac{\mathrm{Br}^{\prime} \mathrm{a}^{\prime} \mathrm{X}}{\mathrm{br}^{\prime} \mathrm{A}^{\prime} \mathrm{X}}\right)$ and barred normal $o^{\prime}\left(\frac{\mathrm{Br}^{\prime} \mathrm{a}{ }^{\prime} \mathrm{X}}{0}\right)$

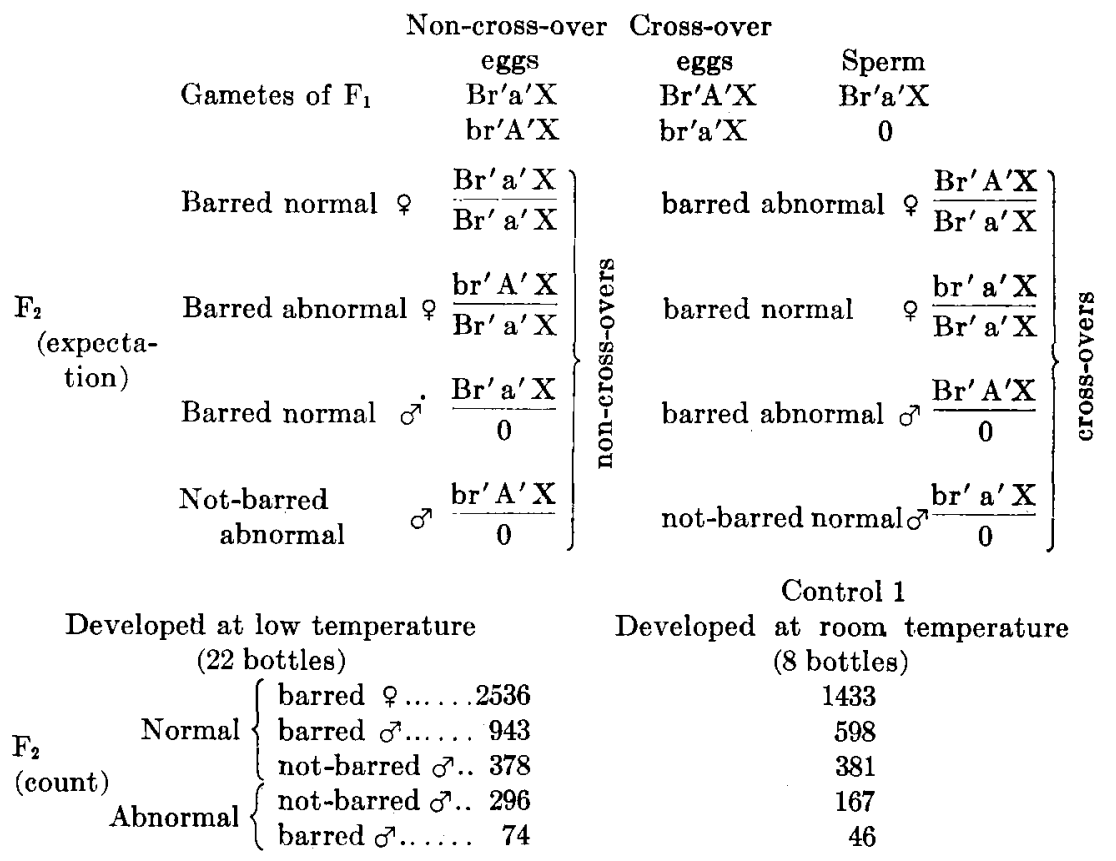

Total number of non-cross-over abnormal males.............463

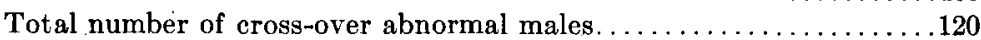

Total number of $F_{2}$ abnormal males....................583

Ratio of cross-overs to total number. . . . . . . . . 20.6 per cent

temperature, are counted together, as the $F_{1}$ parents were identical for both. The bottles were carefully examined, and when the pupa cases opened, the flies, if unable to emerge, were drawn out with needles. Many of the abnormals recorded were thus artificially hatched, and it was only by this method that so large a yield was obtained.

4 In Cross III, the $F_{1}$ should show criss-cross inheritance with respect to factor A only, as the factor for barred is dominant in the female parent. 
In crosses like Cross III, where one or both dominant sexlinked characters entered with the female parent, the 'crossovers' are recognizable only in the male class, since all the $F_{2}$ females carry the factor which was dominant in their grandmother. In crosses where both sex-linked characters are recessive in the female, as in Crosses I and II, the $\mathrm{F}_{2}$ females, as well as males, can usually be used in determining the linkage. In the present experiment, however, the female 'cross-overs' must necessarily be disregarded, since, as will be shown later, female flies carrying $A$ are more often normal than are males carrying $A$.

It is obvious that all of the $F_{2}$ males can not be used to determine the linkage, since some males that are normal, whether barred, vermilion or white, may carry the A factor. The cal-

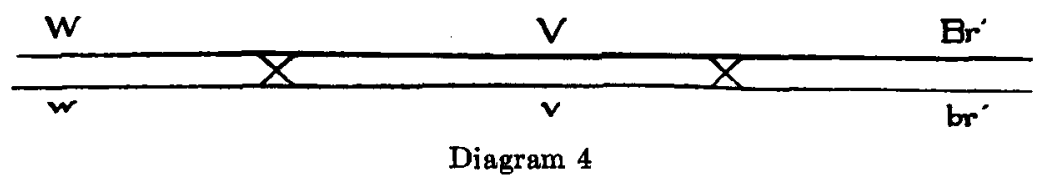

culation of the linkage is, therefore, made on the following basis. Though all of the $F_{2}$ flies are recorded, the abnormal males only are considered in determining the linkage. The ratio between the abnormal 'cross-over' males and the total number of abnormal males is thus regarded as a measure of the distance between the $\mathrm{A}$ factor and the other factor under consideration. This scheme rests upon the assumption that barred, vermilion, white, and red flies, carrying $A$, develop the reduplications to an equal extent. This assumption seems justifiable, as there is no evidence that any interaction takes place between the $\mathrm{A}$ and other factors.

The results given above show that the linkage between the $A$ factor and the three other factors compared above is strongest in the case of vermilion (1.6), much weaker with barred (20.6), and still weaker with white (28.9). Sturtevant ('13) showed that 30.7 per cent of crossing-over occurs between white and vermilion, and Tice ('14) showed that 25.3 per cent of crossing-over took place between barred and vermilion. These three factors may be diagrammatically represented as in diagram 4 . The strength 
of the linkage between vermilion and abnormal indicates that their loci are close together. This conclusion is further supported by the linkage between white and abnormal (28.9) and between barred and abnormal (20.6). These distances are reasonably close to those obtained by Sturtevant, for white and vermilion, and by Tice, for barred and vermilion. Recent work done in this laboratory has shown that a double crossing-over, involving two breaks in the chromosome, may take place when long distances are concerned. When this occurs, the non-crossover classes are increased and the cross-over decreased. Allowing for a larger number of double cross-overs in the present work than in that of Sturtevant and Tice, the results fall within the limits of variation which might be expected if vermilion were as close to abnormal as the per cent of cross-overs (1.6) indicates. It seems hardly necessary to determine on which side of vermilion the A factor is located, since the nature of the character will necessarily exclude it from other linkage experiments.

These results afford additional evidence, were such necessary, of the Jocation of the $\mathrm{A}$ factor in the sex-chromosome and of the identical behavior of this and other sex-linked factors.

\section{THE FACTOR FOR REDUPLICATION A SEMI-LETHAL}

A second control of the above crosses was made by allowing flies of pure abnormal stock to develop at the low temperature until the pupa stage had been reached, when they were removed to normal room temperature. The feature which distinguished this control from the main test was thus not a difference in the environmental conditions, as in the first control, but a difference in the genetic constitution of the flies. The following flies hatehed from this control.

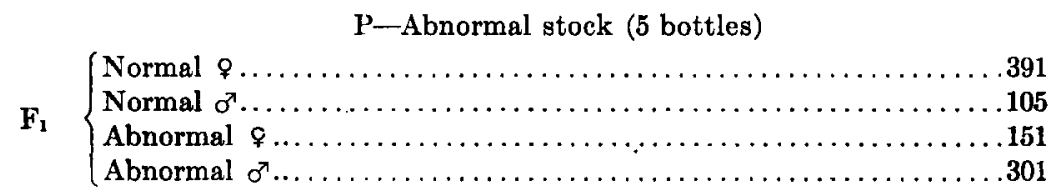

It was necessary to hatch many of these flies artificially, as before, but the normal individuals were perfectly normal. There- 
fore, the low temperatures maintained during the main test were either kept too high or not continued long enough to influence all the flies carrying the A factor, but only by this method could a sufficient number of abnormal flies be obtained. It is important to note that from the low temperature bottles of the abnormal stock, a smaller number of males than females was hatched, and that the larger proportion of the abnormals were males. Thus the low temperature, which has been shown in table 9 to exert a lethal effect on pure abnormal stock, is more fatal to males than to females.

Previous experiments (table 9) have shown that, when pure abnormal stocks develop at low temperature, the per cent of abnormals is increased, but the total number of flies decreased. Abnormal flies are thus much less viable than are flies of wild stocks. However, as the abnormals appear more frequently when the larvae are developed at reduced temperature, the low viability of this stock is much more pronounced under these conditions. In crosses with the wild, when the $F_{2}$ flies have developed at room temperature, those classes which, in the absence of cross-over, carry the factor for abnormality, as the red-eyed flies in Crosses I and II and the not-barred flies in Cross III fall only slightly, if at all, below the other classes. If the $\mathrm{F}_{2}$ flies are raised at reduced temperature, however, these classes fall far below the others. This decreased viability is often noticed in the males alone, for, as stated above, females, even when homozygous for $\mathrm{A}$, are less affected by a low temperature. Upon the males, the factor for abnormality has a definite lethal effect, which is greatly increased by reduced temperature. This fact is well shown by the following figures, in which the $\mathrm{F}_{2}$ recorded above are grouped according to eye character alone:

Cross I

Vermilion normal $\&$ by red abnormal $\sigma^{\pi}$

Red $\circ$

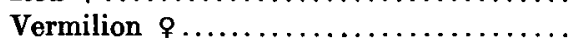

Red $o^{7} \ldots \ldots \ldots \ldots \ldots \ldots \ldots \ldots \ldots$

Vermilion $\sigma^{3}$.
Developed at low temperature 1715 1908 859 1659
Developed at room temperature 980 1016 737 884 
Cross II

White normal \& by red abnormal $\sigma^{7}$

\begin{tabular}{|c|c|c|c|}
\hline & Low & temperature & Room temperature \\
\hline Red $\%$ & & 969 & \\
\hline White o & & 892 & 304 \\
\hline Red $\sigma^{x}$. & & 596 & 345 \\
\hline White or & & 666 & 329 \\
\hline
\end{tabular}

Cross III

Barred normal \& by not-barred abnormal o

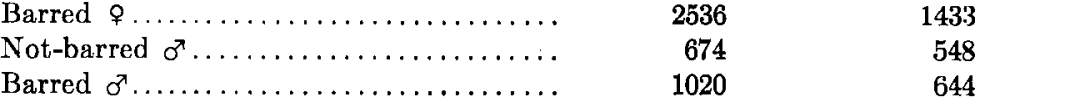

These figures show that the lethal effect is also evident in those classes of males which would not, in the absence of cross-over, carry the factor for abnormality. In Crosses I and II, were there no lethal effect, all four classes should be equal, and in Cross III the number of not-barred and barred males should in each case be one-half that of the barred females. Not only are the red males in Cross I and II and the notbarred males in Cross III far below the other classes, but the vermilion, white and barred males are also low in number. The decreased viability of these groups is directly proportional to the extent to which the vermilion, white and barred factors cross-over with the factor for the normal red-eye. Thus, in Cross I, the number of the vermilion males was only slightly less than that of the red or vermilion females, for only seldom (1.6) does 'crossing-over' affect the vermilion males. In Crosses II and III, the white and barred males showed a larger decrease than did the vermilion males, since the linkage was stronger between abnormal and vermilion than between abnormal and either barred or white. Also, the white males were more affected than the barred males, as 'crossing-over' took place oftener in the case of white (28.9) than in the case of barred (20.6).

It is interesting to contrast the results given above with those obtained by Rawls and by Morgan. The former discovered among her cultures an unusual sex-ratio of two females to one male. Morgan found that this ratio was due to a sex-linked 
factor, one dose of which is fatal to the male. A female homozygous for lethal can never be produced, but a heterozygous female with one dose can survive. In the case of the reduplicating factor A, a single dose may be more or less fatal, depending partly on the environmental conditions during the larval stages. It is evident that the lethal effect was greater when development took place at reduced temperature. This was especially apparent when the first flies began to hatch from the cooled bottles in the crosses given above. Since the eggs had not all been laid at the same time, and since the bottles had been removed to a warm room when the larvae began to pupate, the first flies to hatch were necessarily those which had been longest under the influence of the cold. In the case of a number of bottles, several days elapsed after the first hatching before any red or unbarred males appeared. Vermilion, white or barred males hatched almost from the start, so that the delay in hatching applied to the one male non-'cross-over' class which carried the A factor. This result is entirely in harmony with that given in table 9 and shows that the lethal effect of the A factor varies directly in proportion to the length of exposure to cold. This factor therefore acts as a semi-lethal. If many of the flies in the above experiment had not been artificially hatched, the lethal effect would have been still more pronounced. As practically all the flies which reached the pupa stage were included in the count, it seems probable that the $\mathbf{A}$ factor in many cases exerts its fatal influence during the early stages of development.

\section{SYMMETRY OF REDUPLICATED PARTS}

\section{In Drosophila}

The abnormal legs present a great variety of types, a number of which are here figured. A detailed description of the legs is given with the figures. Special attention has been paid to the symmetry of the extra parts, and its relation to the symmetry of the normal leg. The symmetry is estimated from the manner in which the parts are bent upon each other and from the position of the claws on the last tarsal segment. In the case of the 
first pair of legs of the male, the position of the sex-comb has also proved a reliable guide. If the sex-comb is lacking, or its position uncertain, the symmetry of the first leg is determined by the claws, and the reverse applies when the claws are lacking. If a leg has two parts, that are right and left, the symmetry is indicated as $\mathrm{R}, \mathrm{L}$, the part to the left of the figure being first indicated. Two such parts are designated as secondary. If one of two such secondary parts be again bifurcated into two socalled tertiary parts, the symmetry of the whole is indicated by separating the letters which represent the two secondary parts by a semicolon, thus- $R ; \mathrm{L}, \mathrm{R}$. The letters $\mathrm{X}, \mathrm{Y}$, and $\mathrm{Z}$ are used when the symmetry can not be determined. When a leg has three parts, all of which seem to originate at the same level, the three letters representing these parts are separated by commas, thus- $R, L, R$. When there are more than three parts originating from one leg, colons and then periods are used to separate the letters representing the parts.

A comparison of the legs figured and described in the plates shows that they readily fall into a number of definite types, as follows:

Type a. Simple bifurcation occurring at any level of the leg from coxa to tarsus, and involving many or only a few segments. The two parts so formed may usually be identified as left and right respectively; i.e., they may be considered as mirror images of each other, though one of the two parts is sometimes larger than the other. Examples:

\footnotetext{
Bifurcation at trochanter, figure 30 , second left leg, $R, L$ Bifurcation at femur, figure 14, left leg, $L, R(?)$

Bifurcation at femur, figure 19, right leg, $R, L$ Bifurcation at femur, figure 20, right leg, $R, L$ Bifurcation at femur, figure 22, left leg, $R, L$ Bifurcation at femur, figure 38, left leg, $R, L$ Bifurcation at tibia, figure 35, right leg, $X, Y$
}

Figures 5, 8 and 34 may be of this type, but the legs are too incomplete to determine this definitely.

Type $b$. Bifurcation into two secondary parts and further division of one of the secondary parts into two tertiary parts. This 
is a very common type. Usually the two tertiary parts may be identified as left.and right with respect to each other and that tertiary part that is nearer the undivided secondary is a mirror image of it. Moreover, the undivided secondary, practically without exception, retains the symmetry of the normal leg. Thus if the whole leg be a right, the undivided secondary is a right. Examples:

First division at coxa, left 1st leg, figure 24, L; R, L First division at femur, right 1st leg, figure $23, \mathrm{R} ; \mathrm{L}, \mathrm{R}$ First division at femur, right 1 st leg, figure $18, R ; L, R$ First division at femur, right 1 st leg, figure $16, R ; L, R$ First division at tibia, left 1 st leg, figure $11, L, R ; L$ First division at tibia, left 1 st leg, figure $13, \mathrm{~L} ; \mathrm{R}, \mathrm{L}$ First division at tibia, right 1 st leg, figure $15, R ; L, R$ First division at tibia, left $2 d$ leg, figure $31, L, R ; L$ First division at tarsus, right 1st leg, figure 10, R, L?; R First division at tarsus, left 1st leg, figure 12, L; X, Y

Type c. In examples of this type, there is at most one division of segments, and often the leg is undivided, but two divisions are indicated by the number of claws or sex-combs. Examples: (a) No division of segments, but tarsus with 2 combs and enlarged distal segment having 3 pair of claws, two of which have a common pad. Left first leg, figure 2, L; R, L. (b) A single division of segments resulting in two tarsi, one of which bears three claws. Right first leg, figure 7. (c) A single division of segments resulting in two tarsi, one of which has two sex-combs and probably always two pairs of claws: Division at femur, left first, figure 15, L, R; L; Division at femur, left third, figure $37, \mathrm{~L}, \mathrm{R}$; L; Division at tarsus, right first, figure $6, \mathrm{R} ; \mathrm{L}, \mathrm{R}$; Division at tibia, left first, figure 9, L, R; L.

Type $d$. In examples of this type, three parts proceed from a single undivided segment. I have only two undisputed cases of this type. In one of the two specimens, the outer and inner parts have the same symmetry and they are mirror images of the middle part between them. The symmetry cannot be determined in the other specimen, as the claws are lacking. Examples: Division at first tarsal segment, left first, figure 4, L, R, L; Division at fourth tarsal segment, left first, figure 3. 
Type e. After a single division, resulting in the formation of two secondary parts, each of the latter shows one or more further divisions, involving segments or only parts of segments. Examples: (a) First division at femur and second division involving tarsus of each part. Right first, figure $17, L, R ; L, R$. (b) First division at femur. One of the secondary parts divides into two, and the other into three tertiary parts. First division at the femur. Second division at tibia or tarsus, Left first, figure $19, \mathrm{R}, \mathrm{X} ; \mathrm{L}, \mathrm{R}(?), \mathrm{L}$.

Type $f$. This type is simply a continuation of the process of division seen in Type $b$, and involves a division into two secondary parts, one of which remains single, whereas the other shows several further divisions. First division at femur, second division at tibia, and third and fourth divisions at tarsus. Left first, figure $21, \mathrm{R}: \mathrm{X} ; \mathrm{Y}, \mathrm{Z}$. L.

Type $g$. No division of segments occurs, but parts of abnormal size and shape. Examples: Right first, figure 26; left first, figure 27; left third, figure 32 .

Type $h$. No division of parts, but complete fusion of the two legs of the opposite sides. Example, figure 25, which represents the fused left and right legs of the first pair. In figure 19, of Type e, division has occurred, but in this case, also, the first pair of legs is more or less completely fused.

All of the abnormal legs of Drosophila that I have studied belongs to one of these nine types. Many examples of nearly all the types have been observed, but drawings were made only when a new variety of the type was found. At first sight, these types may seem unconnected by any plan of division. Careful study, however, will reveal the fact that, although the first six types are dissimilar, the difference is one of degree, and not of kind. All have evidently been produced by one or more bifurcations. In Type a, only one division has taken place, and only two parts have resulted. The two parts are mirror images and there is no reason to assume that either of them is duplex in value. The examples of Type $b$ obviously result from two successive bifurcations, the first, which is similar to the single division of Type a, and the second, which affects only one of the 
parts formed by the first division. In Type c, the second division does not involve the division of segments and it is indicated only by the double claws or double combs. It is possible that in these cases, the claws and combs alone, and not the segments between them, should be regarded as duplex, but it seems more probable that such forms represent legs in which the second division is incomplete, or in which the parts formed by the second division have become more or less fused.

The symmetry of the three parts is very definitely regulated. In all examples of the two types- b and $c$ - in which the symmetry of the three parts can be determined, the following relations are clear. The undivided secondary part formed by the first division maintains the true symmetry of the leg. If the leg be a right, the undivided secondary is a right, no matter whether it be the outermost or the innermost of these three parts. The tertiary part next to it is a mirror image of it and the tertiary part farther from it is like it in symmetry. The symmetry of the two tertiary parts appears as though regulated by the symmetry of the undivided secondary part. This conclusion is the only one possible if it be granted that Type $b$ is only a further development of Type a.

The three apparently equal parts in the legs of Type d proceed from one undivided segment. This form of reduplication may seem very different from that just described; but I am inclined to think that it is simply a modification of Type $b$, in which both divisions have occurred at the same level of the leg.

If the process of division, characteristic of the types thus far described, should be further continued, it would lead to the formation of forms such as those described under Types e and $f$. In Type e, both instead of one of the secondary parts, formed as in Type a, divide, and if no further division occurs, a form like that of figure 17 results. It should again be pointed out, however, that a division of the sex-comb may or may not indicate a duplex nature of the part, though the former supposition seems more probable. If, however, there should be a further division, involving only one of the four tertiary parts, five parts, instead of four, would be formed. Four parts might also arise, not as in 
figure 17 , by simultaneous division of both secondary parts, but by a continuation of the process begun in Type $b$. Thus, if the undivided secondary should still remain simplex, and if one of the two tertiary parts, formed by division of the other secondary, should divide, four parts would result. I have no examples of this kind, but figure 21 involves the same process in which the division has proceeded one step further. This leg is particularly interesting, since it shows to what an extent the successive divisions may take place. The respective values of the parts in this leg are very clear.

The symmetry of these legs having four or five parts leads to some further considerations. Since in general, two parts with the same symmetry are not adjacent to each other it is probable that, with each subsequent division, the symmetry of the new parts is regulated by the symmetry of the adjacent parts. We may thus conclude, that a single division, as in Type a, results in the formation of a right and left, either of which may be on the outer side. The symmetry of a part formed by a further division of one of these two is determined, not by any special innate potentiality which it possesses, but by its position with respect to the adjacent parts.

When the abnormal flies developed at low temperature, the legs often showed a greater degree of abnormality than when development took place at normal room temperature. The basal parts were frequently very much enlarged, and sometimes divided, as in figure 36 . In other specimens, no division of the segments had taken place (Type g, figs. 26, 27 and 32). Legs of this type were usually found on flies having other legs which were more or less divided, and as they have never, to my knowledge, been found on flies of the normal wild stock, it may safely be concluded that they, also, are due to the A factor carried by the abnormal flies. All the other types may be explained as due to one or more divisions, which in some cases were indicated only by double combs or by extra claws. Since the division may thus manifestly affect such small parts only, it seems reasonable to conclude that in the abnormally shaped legs of Type $g$, the divisions have affected only parts of the segments, or groups 
of cells. The three groups of teeth linearly arranged in the first tarsal segment of figure 26 , lends support to this view of general subdivision.

It seems probable that the cells of the leg anlage in those flies which carry the A factor are extremely plastic, easily divided, and as easily united when contact occurs.

The results of the study of the symmetry of abnormal legs may be briefly summarized as follows:

1. Extra parts may arise at any level of the leg.

2. The parts contained in the extra appendages are only those which are distal to the point of origin, and all the distal parts are in most cases represented. Figures 2 and 23 are exceptions to this and are probably due to a linear fusion of segments.

3 . The reduplicated parts are the results of a continued bifurcation, and any part may continue to bifurcate although the other parts may show no further division. By four bifurcations one leg may thus form five parts.

4. When a single division takes place, the resulting parts are left and right respectively. When further division of one of the secondary parts takes place, the symmetry of the resulting tertiary parts bears a relation to that of the undivided secondary in that two parts of the same symmetry are never adjacent to each other. The undivided secondary retains the normal symmetry of the leg.

5. After a division, the resulting parts may be more or less fused, and the duplex nature indicated only by a double comb or extra claws. I consider a part as duplex only when some definite structure which is characteristic of that part is duplex, for otherwise one is forced to assume that the entire limb is duplex, whenever any distal part of it shows indication of doubling. Duplex parts, in fact, are usually preceded by proximal parts no larger than those of a normal leg. 


\section{Reduplication in other animals}

Reduplication of the appendages has been found in nature among many groups of animals, but it has been most frequently observed in arthropods, amphibia, and mammals. The extra parts observed in arthropods usually consist of two supernumerary appendages. In mammals and in amphibia, many kinds of reduplication have been found, such as an extra pelvic girdle with two supernumerary limbs (amphibia); one or two extra extremities more or less complete (amphibia, birds, mammals, man); extra digits (cat, man, etc.). The extra parts are often somewhat incomplete or imperfect. In man, polydactyly is the most common form of reduplication. There are various kinds of polydactyly, and in the majority of cases, there is no manifest change in the symmetry of the hand or foot, and the extra digit is apparently a reduplication of one of the normal digits. A new symmetry is, however, sometimes established, as in double hands and feet.

Bateson's pioneer work on "The materials for the study of variation" has done much in bringing together examples of meristic phenomena from all the main phyla. In this work Bateson has described reduplication in insects, crustacea, birds and various mammals, artiodactyls, perissodactyls, cats and man. In his recent work on "Die Vertebraten Hypermelie," Pol has collected more evidence concerning the meristic variations of vertebrates, especially of man, and he has also included a summary of the experimental work on regeneration of limbs of amphibians.

\section{Reduplication in insects}

Bateson has formulated a number of rules to apply to reduplication in insects. The substance of these is as follows: ${ }^{5}$

1. The parts composing extra legs do not as a rule greatly differ from those of the normal legs which bear them.

2. The parts found in the extra legs are those parts which are in the normal leg peripheral to the point from which the extra legs arise, and as rule, no more.

${ }^{5}$ Bateson, Materials for the study of variation, p. 476. 
3. Extra legs may arise from any point on the normal leg, but there is a slight preponderance of cases beginning from the apex of the tibia.

4. It does not appear that extra legs arise more commonly from either of the three normal pairs in particular.

5. Supernumary legs of double structure are sometimes found as two limbs separate from each other nearly or quite from the point of origin, but in the majority of cases their central parts may be so compounded together that they seem to form but one limb, and the essential double character of the limb is not then conspicuous except in the periphery.

Rule I. The long axes of the normal appendage and of the two extra appendages are in one plane; of the two extra appendages one is therefore nearer to the axis of the normal appendage and the other is remoter from it.

Rule II. The nearer of the two extra appendages is in structure and position formed as the image of the normal appendage in a plane mirror placed between the normal appendage and the nearer one, at right angles to the plane of the three axes; and the remoter appendage is the image of the nearer in a plane mirror similarly placed between the two extra appendages.

Bateson states ${ }^{6}$ that "it is practically certain that in no case can a single, viz., an unpaired duplicate of the normal appendage grow from it." Thus, he says, "a limb of one side of the body, say the right, has in it the power to form a pair of limbs, right and left, as an outgrowth of itself, but cannot form a second left limb alone." He explains examples in which there is a single unpaired duplicate of the normal appendage as instances of a supernumerary pair in which only the two morphologically anterior or two morphologically posterior surfaces are developed.

If we compare these conclusions with those obtained in the present study of reduplication in Drosophila, we find that many of the observations and rules of Bateson which are given above are in general confirmed. I have found, however, a greater number of flies showing reduplication of the first pair of legs than of any other, though many flies with extra second or third legs have been observed.

The symmetrical relations which Bateson observed hold for Drosophila in those cases in which two extra parts have grown from the normal leg. The same relations also hold, in general,

${ }^{6}$ Problems of genetics, p. 75. 
for those legs of Drosophila in which there are more than two extra parts, although Bateson had no examples of this kind. Bateson's statement that a right limb can not form a second left limb alone appears arbitrary in the light of the present work, since, in a number of cases, a single unpaired extra part, a mirror image of the normal, has been observed. Since such single extra parts show no indication of doubling, I am not convinced that there is any advantage in regarding them as double. We have thus in Drosophila, legs with from one to four extra parts, the latter having certain definite symmetrical relations to each other and to the normal leg.

4. Comparison between the extra appendages of Drosophila and other animals

Bateson found no examples like those last mentioned, and, since he regarded all insect reduplications as composed of two extra parts grafted upon the normal, he was unable to homologize the variations of insects with those of mammals. If, however, the type which Bateson regarded as universal be considered as only one of a number of types, then the reduplication of both insects and mammals may be shown to result from a more or less continued process of division. If, with this suggestion in mind, the figures given by Bateson and Pol be agajn examined, many reduplications, morphologically very different, will probably be brought into line. It must be remembered, however, that some of the parts formed by the divisions may fail, as in Drosophila, to attain complete development. This is a possible explanation of some of the forms of polydactyly found in man.

\section{Comparison with the regeneration of experiment of Tornier}

The work of Tornier and Fritsch on regeneration has thrown much light on the origin and meaning of the reduplications found in nature. This work is briefly summarized by Pol. Fritsch cut off the hand of Triton, and then, following the method of Barfurth, he made a longitudinal cut in the fore limb. In two cases a hand was regenerated from each of the cut surfaces 
at the end of the forearm. Tornier also performed similar experiments. In one case, he cut off the hind leg of Triton near the hip joint and stretched a thread across the cut stump, so that the femur was practically divided at the cut end. A double limb, with the two feet turned toward each other, regenerated from the cut femur. Tornier carried on a still more interesting series of experiments on tadpoles in which the posterior limb rudiments had just appeared. He found that when the anlage of one side only was cut, three limbs were sometimes formed on that side instead of one. If the anlage of both sides were cut at the same time, six limbs sometimes resulted, an extra girdle with two legs being on each side. In certain regeneration experiments where a single cut was made, only one extra limb was formed, probably due to crowding, and this limb was always a mirror image of the nearer stem limb. When two extra limbs were formed, each was in symmetry with the other if the two were near together, but in symmetry with the nearest stem limb, if they were far apart. Tornier considered the number of parts formed, and the degree of union of the extra parts as dependent upon the space in which the parts developed. Thus, in a limited space, one part might be crowded out, or two parts become more or less fused.

In addition to his experimental work, Tornier carried on a comparative study of reduplication, particularly in insects and in mammals. He concluded that the results of his experiments on amphibia could be applied to the regenerated legs found in insects and to the supernumerary limbs of mammals. He showed that reduplications in insects could be explained as due to injuries resulting from wounds, and extra parts in mammals by a pressure of the amniotic fold upon the embryo. According to this view, the number of cut surfaces and the available space determine the number of supernumerary parts. Thus he explained the formation of one or two extra parts in both insects and mammals.

Further observations were made by Tornier concerning the symmetry of the extra parts in insects, and in mammals. In the beetle, he found that if two extra limbs develop, they are right 
and left respectively, but that if only one develops, it is a mirror picture of the stem leg from which it arises. He furthermore states that the evidence from mammals also indicates that an extra limb is a mirror image of the stem limb.

The experiments and observations of Tornier seem to have been somewhat neglected. They are certainly highly instructive as indicating the fundamental similarity between the extra parts of insects and vertebrates. They are also interesting in that they afford comparison with the results obtained in the present work. Many of the reduplications found in Drosophila, had they been discovered as isolated cases, might readily have been explained as regenerations due to injuries, as Tornier has suggested for similar formations in beetles. It is rather striking that the symmetry of the regenerated parts of insects which Tornier has observed is like that of the extra appendages of Drosophila. There is, however, one main point of difference. In Drosophila the extra legs are not due to injuries, and they are fully formed when the flies hatch. The character is, moreover, inherited, in the sense that the potentiality for division of legs is present in every fly of the abnormal stock, whether or not it is actually realized. The natural conclusion, therefore, is that in the abnormal stock of Drosophila that A factor, acting with the rest of the organism, produces a condition favorable for bringing about repeated divisions of the leg anlage. The separation of the cells of the anlage, as the experimental work on Drosophila has shown, must be brought about more readily when a low temperature is maintained. The experiments have further shown that a low temperature is effective only if applied during the early larval stages. Since this is the case, the low temperature must act in some way not only on the cells of the anlage, but also on the cells which are to give rise to the leg anlage, for at the very early stages the imaginal dises have not yet been formed.

Other work on regeneration, besides that of Tornier, lends support to the conclusion that the formation of the extra parts may be due simply to a separation of the cells of the anlage. For example, Morgan found that, when the head of a Planarian 
was cut off, a single head would regenerate, if no further cut were made. However, if a longitudinal slit were made at the anterior end, or if a wedge-shape piece were removed from the middle of the body, a new head would grow from each of the cut surfaces. The breaking of the solid connection between the cells thus determines the duplex mature of the regenerating end. It therefore seems probable that, in Drosophila, if the cells should be separated at the end of the developing limb, ar complete bifurcation would result, and the structure would be duplex throughout a less or greater extent, depending on the stage of development of the anlage, or upon the length of the separation of the cells. If the separation should occur on the side of a developing limb, either one or two extra limbs might result, depending upon the degree of restriction of the parts.

\section{INHERITANCE OF REDUPLICATIONS IN OTHER ANIMALS}

\section{Inheritance of extra toe in fowls}

With the exception of fowls, little is known of the inheritance of reduplications, and the data collected do not conform to those of ordinary Mendelian inheritance. Davenport, Bateson and Saunders, Punnet and Hurst have done considerable work on the inheritance of extra toes in fowls. Davenport found that the extra toe character acts sometimes as a dominant, and sometimes as a recessive. His results were as follows:

Normal $X$ extra toe $\rightarrow F_{1}$ [21.6 per cent normal 78.4 per cent abnormal]

$F_{1}$ normal $\times F_{1}$ normal $\rightarrow F_{2}$ [73.9 per cent normal 26.1 per cent abnormal]

Davenport concluded that the extra toe character is dominant to the normal, but sometimes so imperfectly so as not to appear. This imperfection of dominance, he found, occurs in homozygous as well as heterozygous individuals, for in some pure bred strains of Houdans or Dorkings having five toes on each foot 3 to 4 per cent of the offspring failed to develop the extra toe on either side. Davenport thinks this is due simply to a weakening of the dominance and not to its reversal. Bateson and Saunders, after working with the same character in the Dorking fowl, also concluded 
that extra toe acts sometimes as a dominant, and sometimes as a recessive. They furthermore state that the recessive normal character may sometimes dominate. Bateson and Punnett found that a single individual may give different proportions of extra toed offspring at different periods.

Hurst's results on fowls are as follows:

In $F_{1}$ the extra toe of the Houdan is dominant over the normal foot of Leghorn, Hamburgh and Cochin. In some cases the dominance is complete, the extra toe being reproduced in its entirety; in other cases the dominance is incomplete, all stages of extra toe being produced, from the most perfect toe down to the mere duplication of the nail; in a few cases the extra toe is found in one foot only, the other foot being apparently normal; in a few cases there is simply an elongated hallux. In $F_{2}$ the hybrid dominant extra toes of $F_{1}$ mated together gave dominant extra toes and apparently recessive extra toes in proportion 3.8:1; mated with pure recessive (no extra toes) they gave dominant extra toes and apparently recessive no extra toes in varying proportions $1: 1.3,1: 1.1,1: 1.4,1: 3.3$.

Hurst concludes that the $1: 3.3$ rates must be due to some abnormal disturbance, since the other results are so nearly uniform. $\mathrm{He}$ therefore regards the case as a true instance of failure of dominance, but thinks it evident that segregation takes place along Mendelian lines. Hurst finds that cases of incomplete dominance in fowls appear to be about twice as numerous as cases of complete dominance.

\section{Inheritance of polydactyly in man}

Polydactyly in man is apparently a dominant, but as Davenport states, polydactyly is difficult to explain on Mendelian principles. Bateson finds that it may appear in the same strain or family under forms morphologically very dissimilar. The general facts of inheritance of extra digits in fowls and in man are thus very similar to those for Drosophila, for in all three the more divided state may sometimes act as a dominant and sometimes as a recessive. In Drosophila, however, the dominance is to some extent dependent upon the environmental conditions. It seems probable that a similar explanation might apply to these other cases also, and that, to obtain a large number of abnormal

THE JOURNAI, OF EXPERIMENTAT, zOÖLOGY, voL. 18, No. 2 
individuals, certain external conditions must be maintained throughout development. Whether or not these and other cases of reversal of dominance or incomplete dominance are the result of environmental conditions, can of course be determined only by future experiments.

\section{All reduplications not dominant characters}

Bateson has stated that the less divided state is usually dominant to the more divided states. Clearly the extra legs of Drosophila as well as the extra digits of fowls and of man, are exceptions to this statement. The mule hoof of swine, reported by Spillman, and the webbed character of the digits of man, reported by Newsholme, do, however, conform to Bateson's rule, since both of these dominate the more divided or normal condition. Thus the less divided state in some animals is a dominant, in others a recessive. I see no reason to suppose that the more divided state should, in all animals, act in the same way-as a recessive or as a dominant. Bateson considers the added divisions to be due either to "the addition of some factor or power which enables the part to divide," or to the "absence of something which in the normal body prevents the part from dividing." In the case of Drosophila, it need only be stated that some germinal change has brought about a new condition of the cells of the leg anlage favorable to bifurcation, but further than this we cannot go.

\section{SUMMARY}

1. Selection aimed to produce races of Drosophila possessing high or low numbers of teeth in the sex-comb resulted in the isolation of races with high and low numbers of teeth; but in neither race was the number of teeth of the average individual higher or lower than the extreme variants in the wild stock.

2. During the course of the selection a mutation, involving reduplications in the legs, appeared. The origin of the mutation was probably not determined in any way by the selection, for repeated selection in a new line was not followed by a similar mutation. 
3. The new character was found to be due to a sex-linked factor, the location of which in the sex-chromosome is close to that of the factor for vermilion eyes.

4. The extra legs sometimes acted as a dominant, and sometimes as a recessive character, and flies homozygous for the reduplicating factor were often perfectly normal.

5. The reduplications were found to be due to some extent to the temperature, as a low temperature, maintained throughout the larval life, was necessary for the production of a Jarge proportion of abnormal flies. Only flies carrying the reduplicating factor, however, could be thus affected by a decrease in temperature.

6. The extra legs were of a variety of types, and the number of extra parts in a single leg varied from one to four. A definite relation in symmetry was found to exist between the normal and the supernumerary parts. It is apparent that the extra parts are formed by one or more bifurcations, and it is suggested that reduplications in other animals may be explained in a similar manner. 


\section{LITERATURE CITED}

Bateson, W. 1894 Materials for the study of variation. Macmillan and Co. 1913 Problems of genetics. New Haven, Yale University Press.

Bateson, W., and Saunders, E. R. 1902 Report I to the Evolution Committee of the Royal Society, London; Harrison.

Bateson, W., and Punnet, R. C. 1905 Experimental studies in the physiology of heredity: Poultry. Report II to the Evolution Committee of the Royal Society, London; Harrison.

Bridaes, C. B. 1913 Non-disjunction of the sex-chromosomes of Drosophila. Jour. Exp. Zoöl., vol. 15, no. 4.

Davenport, C. B. 1906 Inheritance in poultry. Carnegie Institute of Washington, p. 72.

1910 Imperfection of dominance and some of its consequences. Amer. Nat., vol. 44, no. 519.

Hurst, C. C. 1905 Fxperiments with poultry. Report II to the Evolution Committee of the Royal Society, London; Harrison.

Johannsen, W. 1911 The genotype conception of heredity. Amer. Nat., vol. 45 , no. 531 .

Morgan, T. H. 1901 Growth and regeneration in Planaria lugubris. Arch. für Entw., Bd. 13, Heft 1 und 2, p. 202.

1911 Attempt to analyze the constitution of chromosomes on the basis of sex-limited inheritance in Drosophila. Jour. Exp. Zoöl., vol. 11 , no. 4 .

1912 Explanation of a new sex ratio in Drosophila. Science, N.S., vol., 36, no. 934.

Newsholme 1910 A pedigree showing bi-parental inheritance of webbed toes. Lancet, December, p. 1690.

PoL 1913 Die Vertebraten-Hypermelie. Studien zur Pathologie der Entwicklung. Bd. 1, heft 1 .

Rawls, E. 1913 Sex-ratios in Drosophila amphelophila. Biol. Bull., vol. 24, no. 2.

Spillmax, W. 1910 American Breeders' Magazine, vol. 1, p. 178.

Sturtevant, A. H. 1913 The linear arrangement of six sex-linked factors in, Drosophila as shown by their mode of association. Jour. Exp. Zoöl., vol. 14 , no. 1 .

Tice, S. C. 1914 A new sex-linked character in Drosophila. Biol. Bull., vol. 26 , no. 4 .

TonNier, G. 1897 Ủber experimentell erzeugte drei schwänzige Eidechsen und Doppelgliedmaszen von Molchen. Zool. Anz. p. 356.

1901 Verhandlungen des V Internationalen Zoologen Kongresses. Berlin. 


\section{EXPLANATION OF PLATES}

All the drawings were made with camera and Zeiss binocular, paired oculars 3 , paired objectives $a_{\mathfrak{b}}$, the right objective and ocular alone being used. The drawings are reduced one-third the original size, and represent a magnification of $\mathbf{5 7 . 2}$ diameters. The number of teeth in the sex comb is accurately represented. The figures of each of the three pairs of legs are arranged in the plates according to the number of bifurcations of the leg, and begin with those in which the most distal parts only are affected. Unless otherwise indicated, all legs except those drawn are normal, and all legs figured are drawn from ventral view. 


\section{PLATE 1}

\section{EXPLANATION OF FIGURES}

1 Right first leg of wild male, showing coxa, trochanter, femur, tibia and tarsus of 5 segments. The first tarsal segment bears the sex-comb, the teeth of which always point toward the fly when the leg is bent as figured. Tarsus ends in a small pad and 2 claws which curve towards fly when leg is flexed.

2 Right lateral view of left first leg of very abnormal male, developed at low temperature; femur and tibia reduced and twisted, tarsus with 2 sex-combs, 17 and 6 teeth respectively, and 3 pairs of claws on the last of the 4 segments, which probably represents two fused segments. Symmetry L; R, L. Other legs broken or abnormal.

3 Left first leg of female; first three segments of tarsus much thickened, and prolonged distally into three branches of two segments each; claws missing. See also figure 35 which is right third leg of same fly.

4 Left first leg of male. First segment of tarsus very wide (with 3 sex-combs) giving rise to 3 branches of 4 segments each. Symmetry $L, R, L$. Inner branch a left with 2 claws, 14 teeth; middle branch a right with 2 claws, 13 teeth; outer branch a left with 2 claws, 19 tecth.

5 Left first leg of female; proximal part of leg normal; tarsus very short; small branch without claws proceeds from second tarsal segment; probably 5 segments in tarsus. See also figure 20 which is right first leg of same female.

6 Right first leg of male from ventro-lateral view; first tarsal segment bifid; inner branch duplex, as shown by 2 combs of 9 and 10 teeth, and 2 pair of claws; outer claws and comb left, inner right. Outer branch (a right) with a single comb of 11 teeth and with 2 claws. Symmetry $R ; L, R$. The right third leg of same fly had a small elevation on the trochanter.

7 Right first leg of female; lower part of tibia bifurcated, each branch ending in a complete tarsus; outer tarsus (a right) with 2 claws; inner tarsus (a left) with 3 claws.

8 Right first leg of male; first segment of tarsus bifurcated, forming two tarsi; outer branch (a right) with 9 teeth, 2 claws; inner branch (a left?) with groups of 3 and 6 teeth, and incomplete distal portion; 5th segment evidently broken off. See also figure 37 , which is left third leg of same fly.

9 Left first leg of male; tibia bifurcated as in figure 7, ending in two tarsi; outer branch (a left) with 11 teeth and 2 claws; inner branch with claws missing and with double comb on single tarsus. Double comb consists of a right outer of 9 teeth and left inner of 9 teeth. Symmetry L, R; L. 
INFLUENCE OF TEMPERATURE ON DEVEI.OPMENT MILDRED A. HOOE

PLATE 1
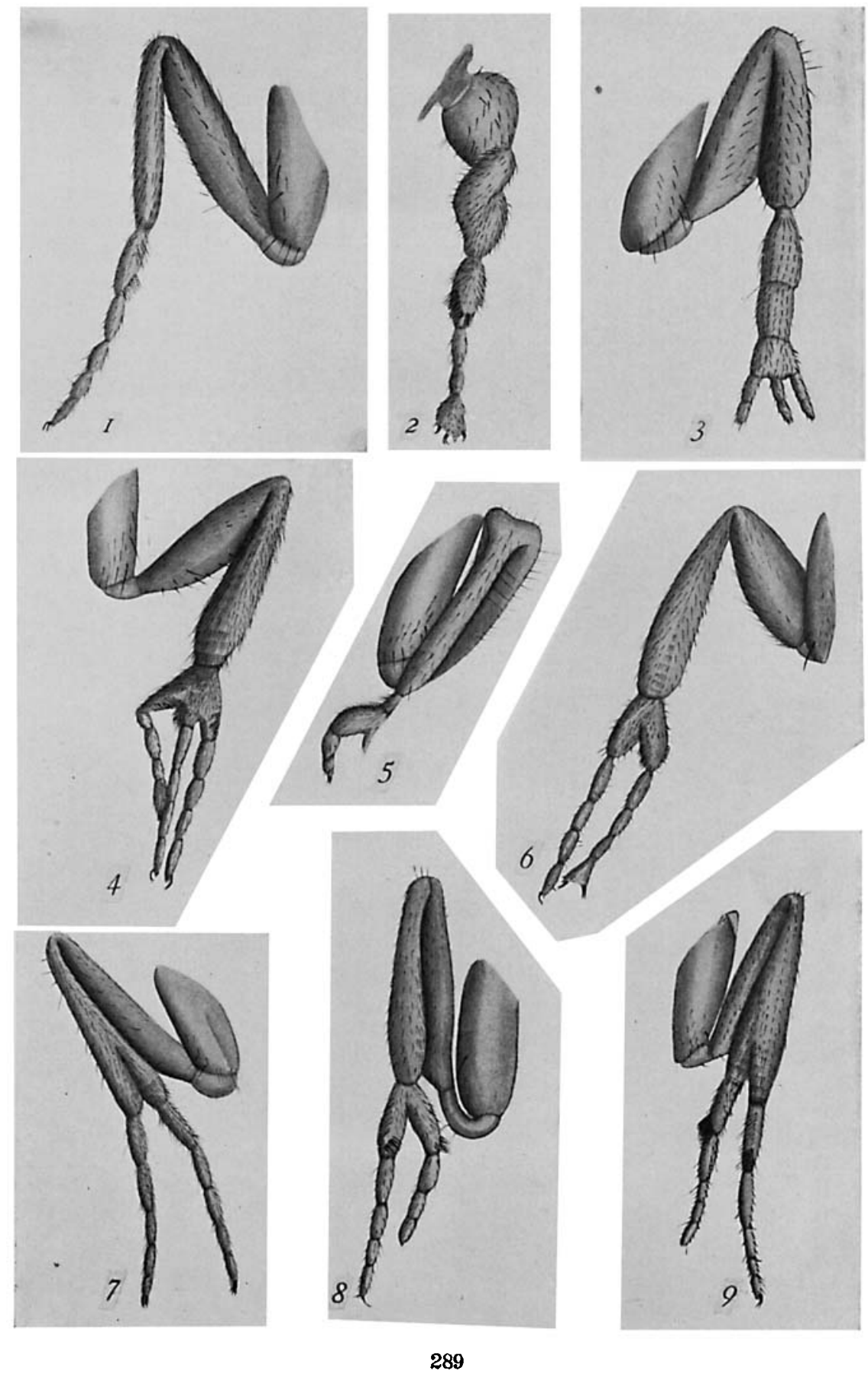


\section{PLATE 2}

\section{EXPLANATION OF FIGURES}

10 Right first leg of male; first tarsal segment with two combs, outer containing 16 teeth, inner 15. From this segment arise two branches, the outer again bifurcated at the second segment, the inner single. Symmetry of the three pairs of claws somewhat uncertain, but probably right, left and right respectively; outer comb probably equivalent to a right and a left combined. Symmetry $\mathrm{R}, \mathrm{L}$ ?; R.

11 Left first leg of male; tibia cleft at distal end, giving rise to a single outer branch (a left) with 12 teeth and 2 claws, and an inner branch, which bifurcates again into a right outer with 10 teeth and 2 claws and a left inner with 13 teeth and 2 claws. Symmetry L, R; L. Apparently this leg is incapable of bending between femur and tibia.

12 Left first leg of male; femur and tibia undivided as in figure 10, but rather broader than normal; tibia ending in two tarsi, the outer duplex, and apparently twisted through $180^{\circ}$, so that the comb is below; inner branch a left with 10 teeth; symmetry of outer duplex branch uncertain.

13 Left first leg of male; tibia split at distal extremity, giving rise to an inner single branch (a left) with 12 teeth and 2 claws and an outer branch with a large segment containing a comb of 21 teeth, which is probably equivilent to a right and a left, and ending in two branches of four segments each. Outer tertiary branch a left with 2 claws, inner a right, also with 2 claws. Symmetry L; R, L.

14 Left first leg of female from lateral ventral view; coxa reduced, trochanter not visible; femur duplex, of very abnormal shape, and ending in one normal tibia and tarsus (left) and one abnormal tibia, apparently fused with the femur, bent upon itself, and ending in a right tarsus. Symmetry $L, R(?)$.

15 First pair of legs of male; tibia of right leg split as in figure 11, to which it is similar; outer branch from tibia (a right) with 13 teeth and 2 claws; inner branch with two combs of 17 and 14 teeth respectively; inner branch bifurcates at second tarsi 1 segment and ends in two tertiary branches with two claws each. Symmetry $R ; L, R$. Femur of left leg gives rise to a left normal leg with 12 teeth and 2 claws, but has also a small, incomplete and duplex branch. Branch has two groups of 10 and 11 teeth on its first segment; tibia of branch may be fused with this segment, or may be represented by the elevation on the femur from which the branch arises. Symmetry $L, R ; L$. See also figure 34 , which is right third leg of same fly.

16 Right first leg of male; coxa overlapped by thoracic plates, usually not represented; femur has a branch from its proximal end, but otherwise gives rise to a normal right leg, with 11 teeth and 2 claws. Branch from femur ends in a short tibia and tarsus, the last segment of which is bifurcated; tarsus of branch has a double comb of 6 and 9 teeth and each of end segments has a pair of claws. Double comb and claws are lefts and rights. Symmetry $R ; L, R$. Left third of same fly missing.

17 Right first leg of male; femur, ending in a normal tibia and also with a branch from the posterior surface; normal tibia ends in two tarsi; an outer left with 8 teeth and claws missing, and an inner right with 12 teeth and 2 claws; branch from femur undivided, but with a double sex-comb of 10 and 9 teeth, which are left and right respectively. Symmetry $L, R ; L, R$. 
INFLUENCE OF TEMPERATURE ON DEVELOPMENT MILDRED A, HOGE
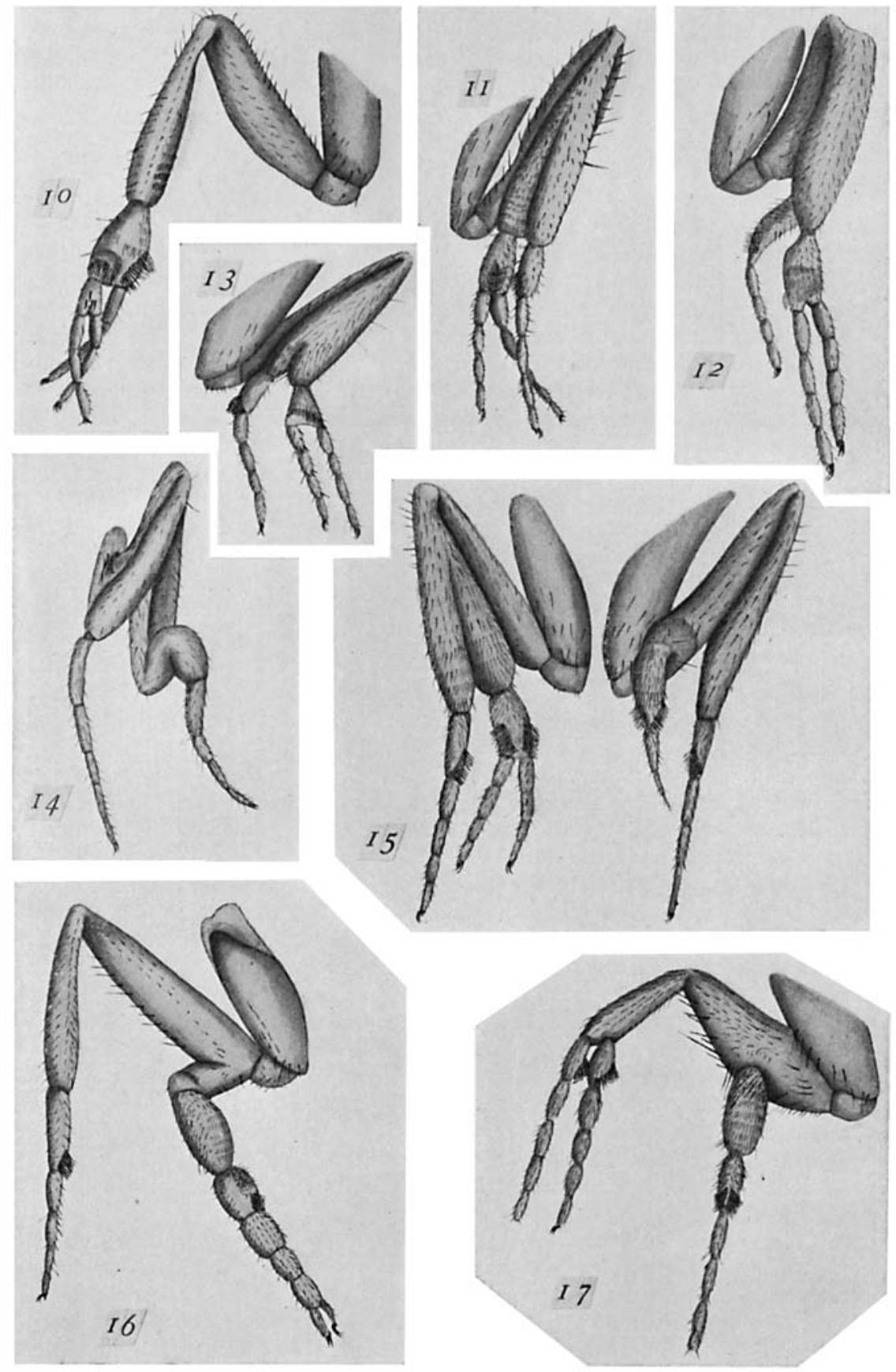


\section{EXPLANATION OF FIGURES}

18 Right first leg of male; trochanter indefinite, femur ending in a normal right tibia and tarsus, but with a large duplex branch from its proximal end; normal tarsus with 12 teeth and 2 claws; outer branch a left with 7 teeth and 2 claws, and with tibia probably fused with femur; inner branch a right with 10 teeth and 2 claws. The main axis of the inner branch is in a more ventral plane than that of the outer. Symmetry $R ; L, R$.

19 First pair of legs of female, completely fused with each other; two separate coxae, trochanters scarcely visible; femora of two sides completely fused with the exception of outer femur of right leg, which is capable of separate motion. $R i g h t$ leg with duplex femur, and 2 tibiae and tarsi; outer femur, tibia and tarsus are those of normal right leg with two claws; inner femur of abnormal size, tibia bent upon itself, and produced into a normal left tarsus with two claws. Lef $t$ leg with two completely fused femora of abnormal size; inner femur ends in a single tibia with two tarsi, the inner of which is a left with two claws, the outer incomplete; outer femur ends in three tibia which are left, right (?) and left respectively; each of these tarsi has two claws. Symmetry of double leg $R, L: R, X ; L, R$ ?, L.

20 Right first leg of female; single coxa, trochanter not visible; two femora, absolutely fused, and prolonged in opposite directions. Outer femur ends in a normal right tibia and tarsus, with two claws; inner femur ends in a bent left tibia and a thickened tarsus with two claws. Symmetry, R, L. See also figurn 5 , which is left first leg of same fly.

21 Left first leg of male; trochanter small, femur bifurcated at its proximal end. Outer part of femur ends in a normal left tibia and tarsus with 11 teeth and 2 claws; inner part of femur is produced into 2 small tibiae, an inner undivided right, the tarsus of which has 29 teeth and 2 claws, and an outer, which ends in a proximal tarsal segment with 32 (?) teeth. From this segment arise two branches, the outer incomplete and again branched, the inner with 4 segments and 1 claw. Symmetry $R: X ; Y, Z$. L.

22 Left first leg of male; coxa and trochanter single, two distinct femora from trochanter; outer a left with normal tibia and tarsus, latter having 11 teeth and 2 claws; inner a right, short and broad, with small tibia, and incomplete tarsus having 10 teeth. Symmetry R, L.

23 Right first leg of male; trochanter enlarged, and giving rise to two femora; outer femur normal and produced into normal tibia and tarsus with 11 teeth and 2 claws; inner femur and tibia short and broad and not bent upon each other; proximal segment of tarsus of inner part bearing two groups of 15 and 9 teeth respectively. This segment ends in 2 small branches, apparently of 2 segments and 1 claw each; outer claw and comb are rights, inner lefts. Symmetry R; L, R.

24 Left first leg of male; coxa double. This specimen had thus two left first legs almost separate from their bases; outer leg with no visible trochanter, and having an enlarged femur ending in two tibia; outer tibia of outer leg normal, ending in normal left tarsus with 12 teeth and 2 claws; inner tibia of outer leg bent upon itself and ending in nearly normal right tarsus with 11 teeth and 2 claws; inner leg with distinct trochanter, left femur and tibia, and incomplete tarsus. Symmetry L; R, L.

25 First pair of legs completely fused, from very abnormal fly, raised at low temperature. Coxae and trochanters may be represented by part above the fused segment, which stands for femora and tibiae. Two normal tarsi, a right with 11 teeth and 2 claws, and a left with 11 teeth and 2 claws, proceed from the long fused segment. All other legs of this fly were either abnormal or broken off. 


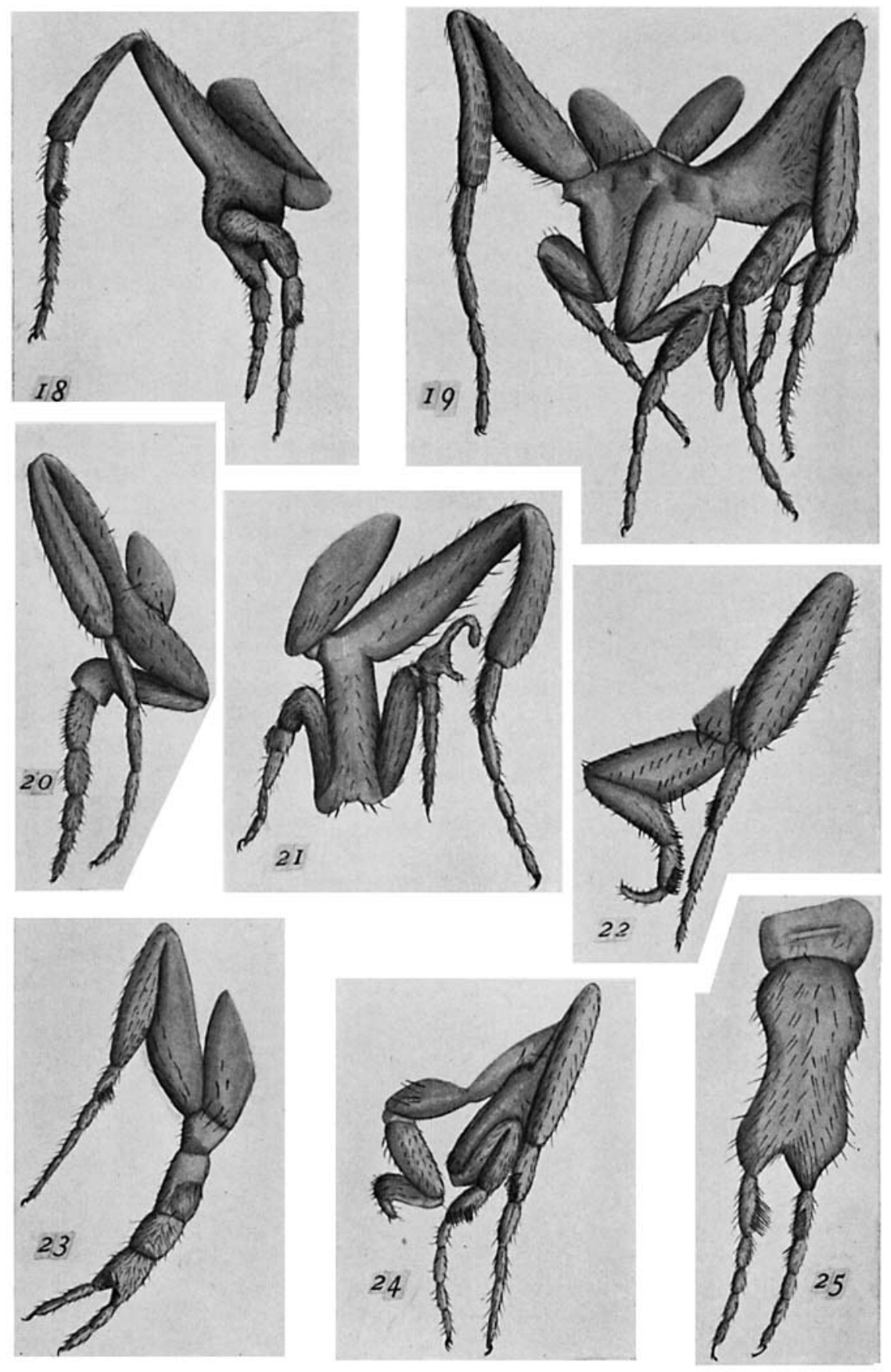


PLATE 4

\section{EXPLANATION OF FIGURES}

26 Right first leg of male fly raised at low temperature; coxa and trochanter indistinct, femur short and thick, tibia bent; tarsus without extra segments but with three discontinuous combs linearly arranged and having 4, 5 and 6 teeth respectively. Right first of same fly bifurcated.

27 Left first leg of male fly raised at low temperature; coxa and trochanter indistinct; femur and tibia short and thick; no extra parts. Other legs of same fly abnormal.

28 Left first leg of male fly raised at low temperature; coxa and trochanter indefinite, femur short and round, tibia short, lower part of leg probably broken off. Other legs of same fly were broken.

29 Right second leg of wild male, showing same parts present in first leg of wild fly, but without sex-comb in the tarsus (compare figure 1). The second leg of a normal male is identical to that of a normal female.

30 Left second leg of male; coxa distinct, trochanter partly divided, each of two parts giving rise tc a femur; outer femur normal, ending in normal left leg with 2 claws; inner femur shorter, ending in a bent right tibia with thickened tarsus having 2 claws. Symmetry $R, L$.

31 Left second leg of male; tibia thick and bifurcated at its distal end, from which proceed 2 tarsi; outer tarsus a normal left with 2 elaws; inner tarsus with single proximal segment which bifureates into two branches of 4 segments each, the outer a right with 2 claws, the inner a left with 2 claws. Symmetry $L, R ; L$.

32 Left third leg of male, with all parts abnormally formed, and relation of proximal segments indefinite; left first of same fly broken.

33 Right third leg of wild male, also without sex-comb. 

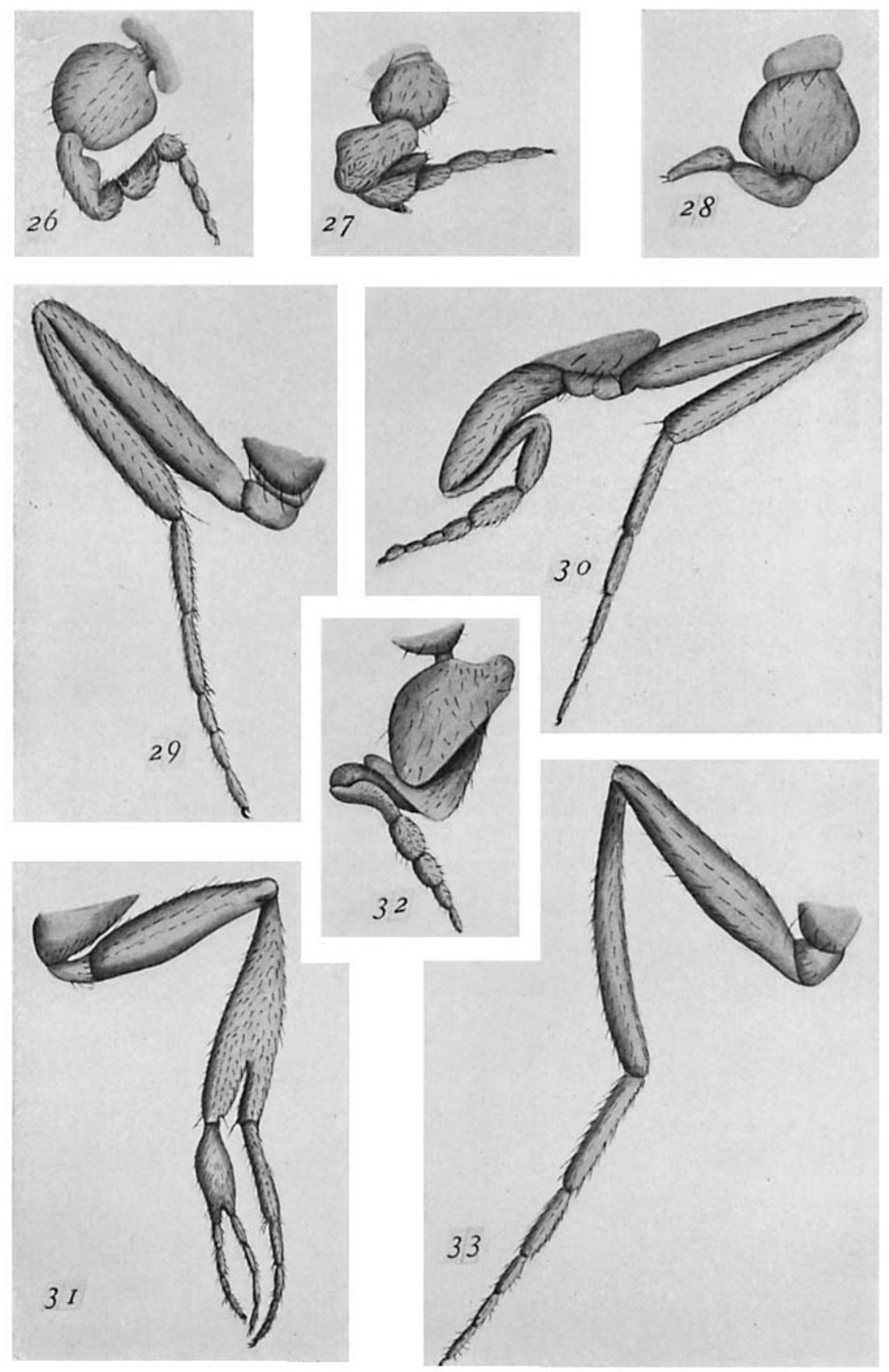


\section{PLATE 5}

\section{EXPLANATION OF FIGURES}

34 Left third leg of male; first tarsal segment enlarged and giving rise to two branches, outer with 4 segments and inner incomplete, and claws of both missing. See also figure 15 , which is first pair of legs of same male.

35 Right third leg of female; lower part of tibia bifurcated, giving rise to two complete tarsi with indefinite symmetry. Inner tarsus with two claws. See also figure 3, which is left first of same female.

36 Stump of right third broken leg of male raised at reduced temperature; figure shows abnormal shape and size of basal parts; distal parts broken off. See also figure 27 , which is left first of same fly.

37 Left third leg of male; femur ending in normal left leg with two claws, and also having a large branch from its posterior surface; tibia of branch short and giving rise to tarsus, which has two pair of claws, a left and a right respectively, on the most distal of its five segments. Symmetry L, R; L. See also figure 8, which is right first of same fly.

38 Left third leg of female; coxa and trochanter single, latter giving rise to two femora; outer femur a left, produced into normal tibia and tarsus with 2 claws; inner femur a right, produced into a short tibia which ends in a thickened tarsus with 2 claws. Symmetry R, L. 
MILDRED A. HOGE

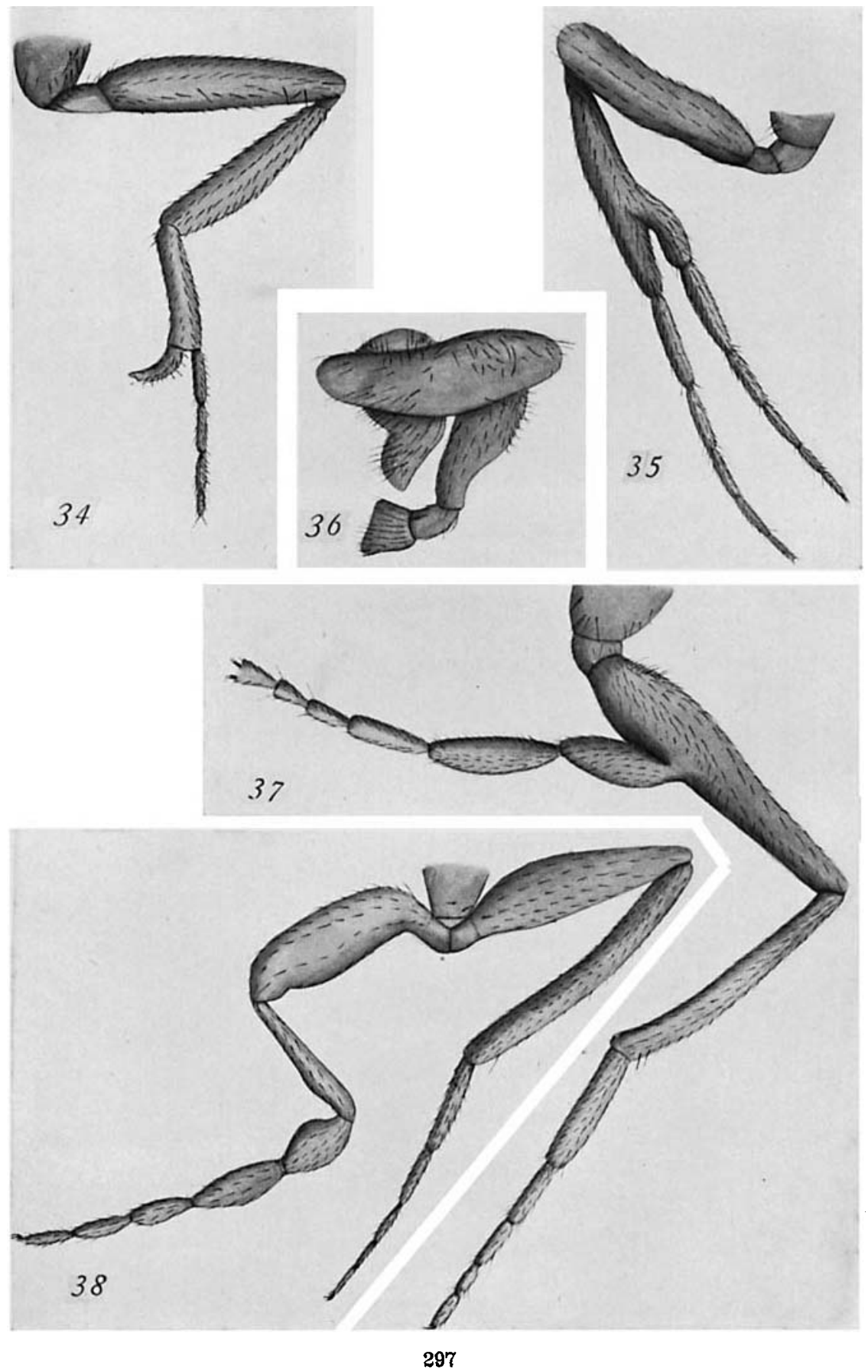

